\title{
Rol de la Cerámica en la Afirmación Social de los Moches del Valle de Santa
}

\section{The Role of the Ceramics in the Social Affirmation of the Moche From de Santa Valley}

Claude Chapdelaine ${ }^{\text {I }}$, Víctor Pimentel ${ }^{2}$ y Jorge Gamboa ${ }^{3}$

\begin{abstract}
RESUMEN
Desde la perspectiva que los moches dominaron y reestructuraron sociopoliticamente el valle de Santa durante la fase IV (450-800 años d.C.), una nueva sociedad Moche se constituyó como provincia del estado expansionista Moche Sur. Nuevas fechas radiocarbónicas confirman una presencia dominante moche que duró más de tres siglos y la densidad de la cerámica típica en los sitios de la fase IV indican sin duda la producción masiva y la promoción del estilo Moche en el valle de Santa. El control politico permitió el desarrollo de una identidad moche en Santa. Las relaciones entre el centro -el sitio Huacas de Moche-y la periferia - el valle de Santa- se discuten a partir de la producción y la distribución de la cerámica doméstica y decorada. Además, intentamos comprender la alfarería local en términos de indicadores sociopoliticos de la sociedad estratificada Moche asentada en este valle, indicando los sitios de producción cerámica y los resultados de una primera fase de análisis de pastas por activación neutrónica.
\end{abstract}

Palabras claves: Moche, expansión, cerámica, identidad cultural.

1 Département d'Anthropologie, Université de Montréal, Québec, Canada. E-mail: claude.chapdelaine@umontreal.ca

2 Département d'Anthropologie, Université de Montréal, Québec, Canada. E-mail: victor.pimentel. spissu@umontreal.ca

3 Proyecto Santa de la Universidad de Montreal, Ancash, Perú. Email: jorgegamboa34@hotmail. com

Recibido: Junio 2007. Aceptado: Diciembre 2007 


\begin{abstract}
From the perspective that the Moche dominated and restructured at the socio-political level the Santa Valley during Phase IV (AD 450-800), a new Moche society emerged as a Province of the expansionist Southern Moche State. New radiocarbon dates support a strong Moche presence lasting more than three centuries, and the high density of typical ceramic on sites of this phase indicates without any doubt the intensive production and promotion of the Moche style in the Santa Valley. Political control allowed the development of a local Moche identity in Santa. The relations between the center, Huacas de Moche, and the periphery, the Santa Valley, will be discussed regarding the production and distribution of domestic and decorated ceramics. We will also try to understand the locally produced ceramic and the socio-political indicators of the stratified Moche society established in Santa by looking at ceramic production centers and at the first results of paste analysis with neutron activation.
\end{abstract}

Key words: Moche, expansion, ceramic, cultural identity.

\title{
INTRODUCCIÓN
}

La producción cerámica es un componente principal en el estudio de las sociedades pretéritas complejas. La preservación prolongada y su abundancia son atributos que la distinguen de otras categorías de artefactos y la convierten en evidencia válida para aproximarse a una historia cultural y explorar una conducta social. La producción alfarera al interior de las sociedades complejas puede ser empleada para evaluar la promoción gubernamental de mensajes ideológicos, políticos y económicos. Pero también puede caracterizar aspectos de carácter artístico, tecnológico o tendencias de consumo promovidas por los dirigentes o los grupos sociales.

La cerámica puede ser estudiada desde diferentes perspectivas y puede relacionarse con varios aspectos del comportamiento humano. Estas consideraciones se aplican sin excepción a la cultura Moche como cultura, como civilización y como Estado. A pesar que utilizamos la cerámica para estudiar los indicadores sociopolíticos en el valle de Santa, el marco analítico de nuestras investigaciones se basa en el enfoque de la cultura total, lo cual significa que para entender una cultura debemos observar y estudiar todos los elementos disponibles. Sin embargo, la cerámica es generalmente el dato 
más apropiado para explorar el comportamiento social complejo. La asociación hecha por los arqueólogos se basa generalmente en algunas observaciones etnográficas generales, en particular sobre los procesos de enculturación entre un maestro y un aprendiz en la producción alfarera (Arnold 1993; Druc 1996).

Un estilo puede permanecer durante varias generaciones sin que se produzcan cambios significativos, pero también es posible que diacrónicamente un estilo cerámico pueda sufrir modificaciones graduales de orden artístico, de consumo y evolución tecnológica o experimentar cambios drásticos creando un equilibrio puntuado. También es posible que algunos objetos menos decorados y de manufactura simple hayan sido utilizados en ámbitos ceremoniales y hayan adquirido una carga simbólica que es difícil de identificar.

En ciertos casos un estilo cerámico puede ser un indicador potencialmente ambiguo del contexto de producción, como habría sucedido durante el dominio inca en Lambayeque, donde se produjeron formas mayormente locales conjuntamente a modelos introducidos por administradores incas (Hayashida 1999). Considerar únicamente al estilo de la cerámica como índice del contexto sociopolítico de una sociedad podría llevar a una conclusión distinta de aquella que emerge con mayor fundamento de una perspectiva que integra la economía del momento y la relación entre artesanos y consumidores de sus productos (Tschauner et al. 1994; Hayashida 1999). Esto no deriva en un impedimento para aproximaciones basadas en la cerámica, sino que señala la necesaria correlación de sus datos con aquellos proporcionados por otras evidencias de actividades humanas.

Las vasijas decoradas y en particular la iconografía representada en la cerámica moche han sido objeto de numerosos estudios e interpretaciones, los cuales señalan que las representaciones religiosas y de representantes de la autoridad ideológica primaron sobre las representaciones de las actividades cotidianas (Donnan 1976, 1978; Hocquenghem 1987; Makowski 1996, 2003; Uceda 2004). Algunas escenas han sido empleadas frecuentemente en la literatura arqueológica para ilustrar casos propuestos de organización sociopolítica e interacción humana prehispánica (Wilson 1988: 340, 1997). Por el contrario, la cerámica llana o doméstica asociada no despertó el mismo interés en los investigadores. Afortunadamente en los últimos años esta situación ha cambiado y se ha incrementado el interés por su análisis, como el necesario complemento al estudio de la cerámica decorada para definir tradiciones artesanales, secuencias cronológicas y procesos sociales. 


\section{EL ESTADO MOCHE SUR}

Antes de continuar con la presentación de la cerámica moche y sobre su significado como indicador social y político en esta sociedad fuertemente jerarquizada, es necesario explicar la presencia moche en el valle de Santa y su entendimiento como el resultado directo del carácter expansionista del Estado Moche Sur, que constituyó un estado territorial que se extendió a lo largo de 200 kilómetros de la Costa Norte del Perú y que tuvo acceso a seis valles (Figura 1). Consideramos que durante la segunda mitad del Período Intermedio Temprano (350-700 d.C.) los moches se desarrollaron como estado multivalle y que el valle de Santa fue una provincia de este estado expansionista cuyo poder estaba centralizado en el sitio Huacas de Moche. La presencia física de una población moche, ya sea ésta reducida o numerosa, ha sido propuesta sobre la base de semejanzas evidentes entre la producción cerámica en los valles de Santa, Moche y Chicama (Larco Hoyle 2001). La comparación de todas las categorías de cerámica sugiere una evolución estilística similar en estos tres valles, cuyas poblaciones habrían compartido una misma ideología, prácticas religiosas y un arte común, pero también con elites y grupos corporativos compitiendo al nivel de valles y sectores específicos de la región.

En la primera mitad del siglo veinte, Rafael Larco Hoyle (1938, 1939, 1948, 2001) definió las principales características de la cultura Moche y formuló una secuencia cerámica compuesta de cinco fases: I a V (Larco Hoyle 1938, 1939, 1948). Durante la última década su vigencia y aplicación para explicar una misma evolución en todo el territorio bajo la influencia de la cultura Moche han sido cuestionadas, notándose una serie de características que permiten establecer dos grandes áreas de desarrollo, separadas geográficamente por el desierto de Paiján. El área septentrional se denomina Mochica-Norte y el área meridional Mochica-Sur (Kaulicke 1992, 1994; Castillo y Donnan 1994; Bawden 1996). Las características observadas por Castillo y Donnan (1994: 177-178) permiten reconocer una tradición cerámica Mochica-Norte distinta del área Mochica-Sur. Las evidencias señalan que los pueblos del territorio Mochica-Norte compartieron una serie de elementos con los pueblos del territorio Mochica-Sur, participando ambos de una misma cultura, pero al mismo tiempo distinguiéndose y manteniendo una propia identidad. 


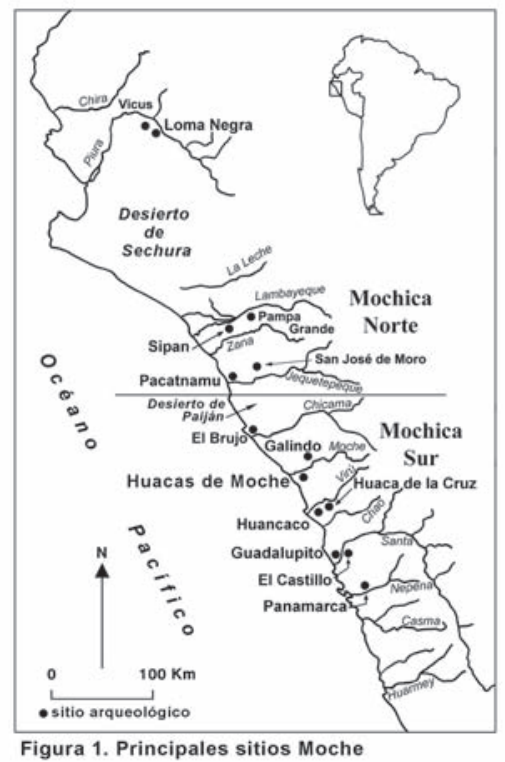

Figura 1. Principales sitios moche de la costa norte del Perú y delimitación de los territorios Moche Sur y Moche Norte.

Figure 1. Main moche sites in the Northern coast of Peru and Southern and Northern Moche territory delimitation.

Sin embargo, la secuencia estilística de la cerámica moche establecida por Larco Hoyle $(1938,1939,2001)$ sí se aplica en el territorio Moche Sur. El incremento del territorio moche durante la Fase III parece estar asociado a una intensificación de la integración cultural y política entre los valles de Moche y Chicama y el área entre Virú y Santa. La Fase IV habría estado vinculada a la consolidación de un sistema que comprendió los valles de Chao, Santa y Lacramarca así como diversas secciones de los valles de Virú (Strong y Evans 1952; Bourget 2003), Nepeña (Proulx 2004) y posiblemente Casma (Wilson 1995) y Huarmey (Prümers 2001). El sitio Huacas de Moche habría ejercido un control hegemónico sobre gran parte de este territorio (Moseley 1992; Shimada 1994a, 1994b; Chapdelaine 2003a, 2004a, 2004b; Uceda y Tufinio 2003). La Fase $V$ en cambio atestiguó una reorientación del rol de los moches en valles como Santa, donde las vasijas finas Moche V habrían ingresado sólo como artículos de intercambio con elites locales y autónomas (Donnan 1973; Pimentel y Paredes 2003). A diferencia de algunos sectores del área septentrional de la Costa Norte, no se ha logrado reportar para los sitios entre Chicama y Santa una producción local de piezas cerámicas combinando formas y motivos moche y wari, tanto en versiones bicromas como policromadas, como las halladas en el valle de Jequetepeque (Castillo 2003). 
Existe para el valle medio de Santa el reporte de Donnan (1973) de piezas cerámicas policromas del Horizonte Medio, sin embargo ese conjunto de botellas con cuerpo en forma de gota halladas en un contexto funerario podría corresponder a objetos de alta calidad intensamente traficados durante inicios del Horizonte Medio.

Es necesario preguntarnos si el estilo Moche Sureño era excluyente, distinguiendo a poblaciones usuarias de otras poblaciones no moche o si era empleado como una herramienta incluyente, fortaleciendo ideologías y jerarquías sociales multiétnicas. La respuesta a esto debe incluir el reconocimiento de un proceso de por lo menos 400 ańos, período durante el cual la evolución de estrategias e identidades demarcó la presencia moche en Santa.

\section{La presencia moche en el Valle de Santa}

A mediados del Período Intermedio Temprano, antes de la llegada de los primeros colonos moche al valle de Santa, la cultura local compartía muchos rasgos con la cultura Gallinazo del valle de Virú. De hecho, la cerámica del Período Suchimancillo del valle de Santa (Wilson 1988) puede relacionarse con varios tipos cerámicos contemporáneos en el valle de Virú, tales como Castillo Llano, Valle Llano, Castillo Modelado, Castillo Inciso y Gallinazo Negativo (Bennett 1950; Strong y Evans 1952; Fogel 1993). La cerámica gallinazo posee características propias al nivel técnico, estilístico y formal que permiten diferenciarla claramente de la cerámica moche en el valle de Santa. Los hallazgos de filiación recuay en varios contextos arqueológicos de tipos habitacional, ritual y funerario asociados a una ocupación gallinazo o moche (Chapdelaine et al. 2003) en el valle de Santa, constituyen evidencias de la interacción de los pueblos altoandinos con los pueblos de la costa. Objetos de cerámica y tejidos de procedencia serrana o fabricados según las técnicas de la sierra posiblemente formaban parte de las redes de intercambio entre ambas regiones. Parte de la cerámica recuay en el valle de Santa probablemente se produjo en la zona de Pashash o en el Callejón de Huaylas. Esta cerámica formaba parte de una tradición de alfarería fina y doméstica diferente de la Moche, pero con afinidades tecnológicas y estilísticas con la tradición Gallinazo (Grieder 1978; Wilson 1988).

La presencia moche en el valle de Santa fue propuesta desde los estudios pioneros de Larco Hoyle $(1938,1939)$, luego reafirmada por Donnan (1973) y Wilson (1988) sobre la base de similitudes entre la cerámica y otros objetos típicos del estilo Moche que se encuentran en los valles de Moche 
y Chicama con aquellos provenientes del valle de Santa. Para explicar la presencia moche en el valle de Santa se favoreció la idea de la conquista territorial y la guerra (Wilson 1988, 1999). Frente a esta posición, nos preguntamos si realmente este valle había sido incorporado por los moches mediante una conquista militar o si más bien hubo una expansión cultural ligada a una asimilación gradual de las elites locales y su adhesión voluntaria a la esfera de influencia moche, lo cual conllevó así a una conquista ideológica. En este sentido el objetivo general del Proyecto Santa de la Universidad de Montreal (PSUM) se orientó a precisar la naturaleza de la presencia moche en el valle de Santa, evaluar su duración y comprender los mecanismos que explican su presencia ${ }^{1}$.

Como consecuencia de la primera fase de nuestro programa de investigación, además de haber documentado la presencia moche en varios sitios de la parte baja del valle de Santa, particularmente en los sitios El Castillo, Guadalupito, Hacienda San José, Huaca China, GUAD-88 y GUAD-121 (Figura 2), ahora podemos estudiar la presencia moche en el valle de Santa dentro de un marco cronológico preciso (entre 300 y 800 años d.C. según 28 fechas radiocarbónicas) y apoyarnos en numerosas colecciones conformadas por una gran variedad de restos culturales. Más de 50 sitios moche de los 205 sitios identificados por Wilson (1988) han sido recorridos, evaluados y sido objeto de una recolección de superficie con la finalidad de formar colecciones de objetos diagnósticos (Chapdelaine y Pimentel 2001, 2002; Chapdelaine et al. 2003, 2004). Basándose en las investigaciones arqueológicas previas (Wilson 1988; Donnan 1973) y los resultados de nuestras excavaciones en sitios moche de este valle, la abundancia de objetos típicos de la cultura Moche, por ejemplo floreros y huacos retratos, sobrepasa ampliamente la posibilidad de explicar esta profusión como resultado de intercambios. Además numerosos cementerios que incluyen únicamente alfarería moche y la existencia de construcciones monumentales de carácter público, las estructuras arquitectónicas, el estilo de los artefactos y los entierros son todos identificables con lo que conocemos de la cultura Moche. Es evidente, en nuestra opinión, que la presencia moche en el valle de Santa debe explicarse en gran parte por una extensión territorial del Estado Moche, lo cual implica un importante movimiento de personas, una migración que toma la forma de una invasión a partir del momento en que los moches controlan el acceso a las nuevas tierras irrigadas. Además, los nuevos dirigentes debieron tratar con la población local que seria asimilada parcialmente y/o desplazada hacia la parte media y alta del valle de Santa (Chapdelaine 2004c). 
A partir del análisis preliminar de los nuevos datos recolectados por el PSUM, surge una perspectiva histórica con un marco cronológico de por lo menos 400 ańos y que abarca principalmente dos fases estilísticas distintas: Moche III (ca.300-500 d.C.) presente principalmente en el sitio El Castillo de Santa, y Moche IV (ca. 500-750/800 d.C.) representada por múltiples asentamientos en ambas márgenes del valle y en el sector anexo de Lacramarca, con ocurrencia menos frecuente de materiales Moche $\mathrm{V}$ en sitios como El Castillo de Santa (Chapdelaine y Pimentel 2001) y Huaca Hedionda (Donnan 1973; Wilson 1988) y en los sistemas de caminos conduciendo al valle de Chao (Pimentel y Paredes 2003). La producción y la distribución de la cerámica moche durante los cuatro siglos de este capítulo de la prehistoria regional nos permiten una mejor comprensión de las diversas tendencias y los comportamientos asociados a la edificación de esta nueva sociedad en el valle de Santa, la cual implicó un contacto inicial entre las entidades gallinazo locales y los grupos portadores del estilo Moche III, una probable intensificación de relaciones económicas e ideológicas entre estas entidades y la posterior dominación moche sobre el territorio local con el establecimiento de un nuevo centro regional en Guadalupito y el proyecto de expansión agrícola en Lacramarca. El resultado fue la formación de una nueva sociedad jerarquizada Moche en el valle de Santa que habría reproducido inicialmente la estructura original de líderes provenientes de los valles de Moche y de Chicama (Chapdelaine 2003b, 2003c; Pimentel 2004a, 2004b), pero que pudo experimentar un proceso final de emergencia de una identidad moche local inmersa en la esfera de interacción norcosteña de la segunda mitad del Periodo Intermedio Temprano, y que aparece evidente en la emergencia de grandes cercaduras con cerámica Moche IV en la margen sur del valle de Santa (Gamboa 2004, 2005: 164, 175-176).

A partir del análisis preliminar de los nuevos datos recolectados por el PSUM, surge una perspectiva histórica con un marco cronológico de por lo menos 400 ańos y que abarca principalmente dos fases estilísticas distintas: Moche III (ca. 300-500 d.C.) presente principalmente en el sitio El Castillo de Santa, y Moche IV (ca. 500-750/800 d.C.) representada por múltiples asentamientos en ambas márgenes del valle y en el sector anexo de Lacramarca, con ocurrencia menos frecuente de materiales Moche V en sitios como El Castillo de Santa (Chapdelaine y Pimentel 2001) y Huaca Hedionda (Donnan 1973; Wilson 1988) y en los sistemas de caminos conduciendo al valle de Chao (Pimentel y Paredes 2003). La producción y la distribución de la cerámica moche durante los cuatro siglos de este capítulo de la prehistoria regional nos permiten una mejor comprensión de las diversas tendencias y los comportamientos asociados a la edificación de esta 
nueva sociedad en el valle de Santa, la cual implicó un contacto inicial entre las entidades gallinazo locales y los grupos portadores del estilo Moche III, una probable intensificación de relaciones económicas e ideológicas entre estas entidades y la posterior dominación moche sobre el territorio local con el establecimiento de un nuevo centro regional en Guadalupito y el proyecto de expansión agrícola en Lacramarca. El resultado fue la formación de una nueva sociedad jerarquizada Moche en el valle de Santa que habría reproducido inicialmente la estructura original de líderes provenientes de los valles de Moche y de Chicama (Chapdelaine 2003b, 2003c; Pimentel 2004a, 2004b), pero que pudo experimentar un proceso final de emergencia de una identidad moche local inmersa en la esfera de interacción norcosteña de la segunda mitad del Periodo Intermedio Temprano, y que aparece evidente en la emergencia de grandes cercaduras con cerámica Moche IV en la margen sur del valle de Santa (Gamboa 2004, 2005: 164, 175-176).

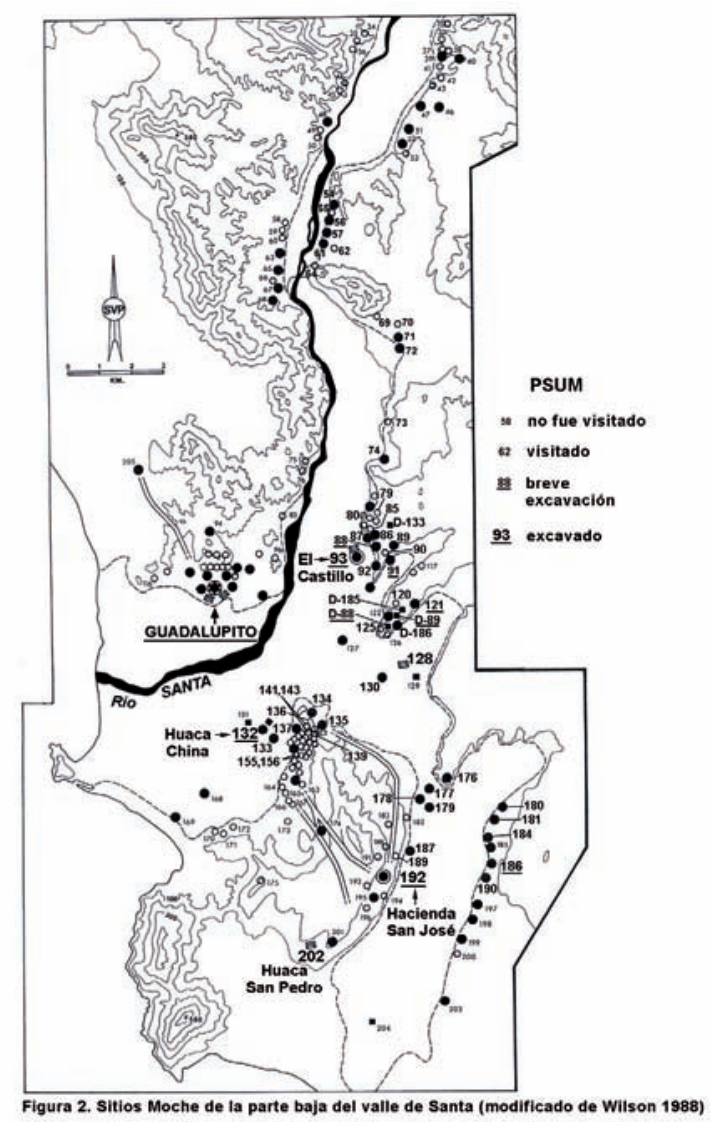

Figura 2. Localización de los sitios moche de la parte baja y media del valle de Santa.

Figure 2. Moche sites location in the lower and mid Santa valley. 
Las evidencias de la fase Moche III se concentran en la parte baja del valle de Santa (Chapdelaine y Pimentel 2003; Chapdelaine et al. 2003; Donnan 1973). Durante esta fase El Castillo alcanzó una notable importancia. Este sitio fue inicialmente un centro de primer orden de la cultura Gallinazo y se transformó luego en un centro moche muy importante, tal como lo evidencian la construcción de la Huaca con murales y el sistema de terrazas, donde se realizaban principalmente actividades de carácter administrativo. Los testimonios en la parte alta de El Castillo permiten sostener la idea del mantenimiento de la población gallinazo después de la llegada de los moches (Chapdelaine et al. 2003: 52-56).

En cambio, la presencia Moche IV abarcó toda la parte baja del valle de Santa y del valle de Lacramarca, que está localizado inmediatamente al sur. En efecto, durante esta fase se produjeron transformaciones locales profundas: a) La incorporación de la anteriormente desértica y deshabitada zona de Lacramarca, que fue transformada en valle cultivable mediante la construcción de canales de irrigación, la creación de tierras agrícolas y el asentamiento de decenas de asentamientos entre los cuales destacan los sitios Huaca San Pedro (GUAD-202) y Hacienda San José (GUAD-192), que constituye el sitio habitacional moche de mayor extensión en el valle de Lacramarca (Wilson 1988: 207); b) La emergencia del sitio Guadalupito (GUAD-111 y GUAD-112) localizado en el sector de Pampa de los Incas, un centro urbano compuesto por una extensa zona residencial y por edificios públicos que constituyen la máxima expresión del poder moche en el valle de Santa, con una población de status social variado y actividades económicas diversificadas, portadora del estilo Moche IV; y c) El funcionamiento de los primeros conjuntos arquitectónicos amurallados de planta rectangular o cercaduras (GUAD-121 y GUAD-135), ubicados en el área limítrofe entre los valles de Santa y Lacramarca, cuyos ocupantes compartían, igualmente a los de Guadalupito, la tradición cerámica Moche IV (Gamboa 2004).

\section{El ROl DE LA CERÁmica EN EL DESARRollo DEL estado Moche SUR}

La cerámica moche fue reconocida desde inicios del siglo veinte como la más diversificada y compleja en representaciones escultóricas de América del Sur y su alta calidad fue la razón principal para su presencia en los mejores museos del mundo. Para nosotros esto significa que la cerámica moche no presenta problemas de identificación, si es que los fragmentos o las vasijas completas son similares a los modelos conocidos en los valles centrales de Moche y Chicama. El único problema relacionado con su identificación y autenticidad es la imitación de esta cerámica, lo cual es posible mediante la 
obtención y utilización de moldes. La alta calidad alcanzada por los alfareros moche es el criterio para distinguir la verdadera cerámica moche de las imitaciones. Sin embargo, debemos indicar que la calidad de la cerámica al interior de la producción artesanal moche es variable y que existen vasijas de mediana calidad en el propio sitio de Huacas de Moche. La presencia de una gran cantidad de cerámica similar o virtualmente idéntica a la cerámica de estilo Moche proveniente de los valles de Moche y Chicama permite la identificación del origen moche de la mayoría de alfareros y de los usuarios de esta cerámica. Debemos igualmente tomar en consideración la presencia de otros artefactos asociados a diferentes contextos arquitectónicos y funerarios en cualquier intento para determinar el origen étnico de un grupo. No cabe duda que la cerámica moche es un buen indicador de etnicidad, pero no debemos olvidar que otros rasgos culturales como son los textiles, adornos personales, peinados, tocados y tatuajes por citar algunos, son también indicadores culturales que combinados con la cerámica permiten una mejor identificación de la filiación étnica de un grupo.

Según los arqueólogos que investigan las sociedades que alcanzaron el nivel del estado, la producción cerámica pudo ser utilizada como herramienta ideológica para promover a la nueva elite gobernante (Moseley 1992). Detrás de este enunciado que sirve para explicar el carácter expansionista del Estado Moche se encuentra la producción masiva de vasijas de alta calidad decoradas con exquisitos diseños de línea fina y sorprendentes representaciones antropomorfas, zoomorfas y fitomorfas moldeadas. Un paradigma importante de los estudios sobre la cultura Moche ha sido el de proponer que los ceramios decorados, que se encuentran en contextos funerarios y conjuntos residenciales y que han sido descritos como objetos rituales o de elite, fueron vehículos para la transmisión de mensajes políticos, económicos e ideológicos (Bawden 1994, 1996; Donnan 2004; Donnan y McClelland 2004). Esto significa que la cerámica puede ser considerada como herramienta para promover las metas del Estado. Por lo tanto en el caso del valle de Santa, la cerámica moche habría servido para incorporar a los grupos locales de filiación gallinazo bajo su dominio. Sin embargo, los datos del PSUM no permiten sostener esta hipótesis, sino más bien la idea de un movimiento de población de origen moche hacia el valle de Santa. Al parecer la población local se mantuvo separada de los primeros colonos y siguió produciendo su propio estilo de cerámica por varias generaciones hasta que los moches tomaron el control político total de esta región a principios de la fase IV (aproximadamente entre los años 500 y 600 d.C.). Esta cohabitación duró unos 150 ańos después del establecimiento de los moches en El Castillo, primer sitio importante de la fase III en el valle de Santa. 
La rica iconografía moche que decora las vasijas y otros objetos de cerámica tales como figurinas, instrumentos musicales, máscaras, piruros y cucharas ha sido analizada por expertos que han identificado la existencia de varios temas iconográficos (Donnan 1978; Hocquenghem 1987; Castillo 1989; Bourget 2001; De Bock 2003; Makowski 2003). Los rituales religiosos, la reproducción del mundo natural y la guerra son algunos de los temas que predominan en las representaciones de las vasijas pintadas y escultóricas elaboradas por los artistas moche. Muchos problemas de investigación se han formulado utilizando escenas iconográficas específicas para promover o para verificar una idea o un comportamiento. Por ejemplo Wilson (1988: 339-340) seleccionó algunos floreros para ilustrar la guerra y su teoría sobre la conquista del valle de Santa por un ejército moche (ver también Arkush y Stanish 2005; y para una visión más amplia Arkush y Allen 2006).

El rol y la importancia de la cerámica moche en el valle de Santa deben ser considerados desde una perspectiva sociopolítica particular de carácter intrusivo. Es importante mencionar que originalmente la cerámica moche y todos los significados que ella podría haber contenido fueron llevados al valle de Santa e impuestos a la población local. Este panorama se basa en la naturaleza del Estado Moche Sur, un estado territorial con una organización política centralizada predispuesta a ampliar su territorio en la medida que su naturaleza expansionista encajaba con su estructura sistémica. Al estudiar la cerámica moche del valle de Santa, es esencial aceptar la idea según la cual este producto era disponible dentro de un sistema de clases basado en la desigualdad y en los privilegios de la clase alta, que tenía acceso diferenciado a las mercancías y a los recursos. La cerámica moche jugó un rol de gran importancia, entre los siglos IV y VII de nuestra era, en el desarrollo de una nueva sociedad en la parte baja del valle de Santa y no era ajena a los eventos y procesos que ocurrían en los valles más al norte. Estilística y tecnológicamente la cerámica moche del valle de Santa, es similar a la que se encuentra en los sitios urbanos y rurales de los valles de Moche y Chicama (Donnan y Mackey 1978: 65-211; Russell et al. 1994, 1998; Franco et al. 2003; Gumerman y Briceño 2003).

La elite de un estado prehispánico tenía necesidades económicas: cosechas estables, productividad y excedentes que permitieran la construcción de templos, acueductos, caminos, canales de irrigación, fortalezas, palacios y residencias de la elite; necesidades militares: destacamentos de soldados, ejército permanente, armas, control del territorio, fuerzas de la ley y de protección de las propiedades estatales; necesidades ideológicas: templos, palacios, capillas, banquetes, prisioneros para los rituales y la producción de 
símbolos a manos de artesanos especializados a tiempo completo. De todas estas necesidades, la cerámica era de particular importancia para las necesidades económicas así como para los objetivos ideológicos. Es necesario mencionar que la cerámica moche fue el producto de un grupo foráneo que había conquistado y ocupado un valle extranjero a través de una serie de acontecimientos de largo plazo que duraron probablemente 400 años. En este contexto particular es evidente que la cerámica moche cumplió un papel importante en el desarrollo de la nueva sociedad Moche en el valle de Santa. Basándonos en los datos arqueológicos reunidos por el PSUM, el objetivo central de esta contribución consiste en determinar la importancia que tuvo la cerámica decorada -generalmente vinculada a la elite- y la cerámica utilitaria en la afirmación social de los mochicas del Santa, para luego proporcionar argumentos que nos permiten sostener que la cerámica moche fue un fuerte indicador étnico (Figura 3).

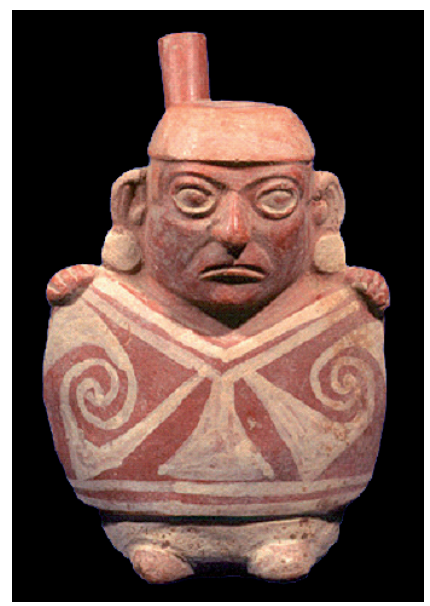

Figura 3. Vasija de la fase Moche III de un hombre presentando un tejido (Procedencia: tumba del Conjunto \#15 de la zona urbana del sitio Huacas de Moche).

Figure 3. Moche III phase vessel depicting a man with a textile (Proceeds from: Conjunto \#15 tomb from the urban area of Huacas de Moche site).

\section{Producción y distribución de la cerámica Moche en el Valle DE SANTA}

Los sitios moche de Santa y Lacramarca muestran en la superficie y en las áreas excavadas la presencia constante de piezas decoradas y no decoradas similares a las que se encuentran en los valles de Moche y Chicama (Figuras $4,5)$. La mayoría de tiestos muestran un control adecuado de cocción en 
atmósfera oxidante, pero ocurren piezas de quemado imperfecto o piezas deformadas durante el quemado (Figuras 6, 7). El uso de pigmento negro sobre engobes crema y rojo generó piezas con pintura tricolor, usuales en sitios de las fases Moche III y IV. A partir de la fase III se elaboraron cuencos finos que reproducían en pequeña escala la morfología de grandes tinajas y ollas de cocina. Si bien ocurren piezas con alta inversión de trabajo en la decoración pintada, también encontramos una gran variabilidad en el grado de esfuerzo puesto en el pintado y pulido de piezas tales como cucharas, cuencos, cántaros y ollas, lo cual nos sugiere la existencia de una diversidad de valores cualitativos atribuidos por los usuarios a la cerámica, pero también que es necesario reevaluar la dicotomía "cerámica fina y doméstica» al existir productos cerámicos que enlazan estos extremos.

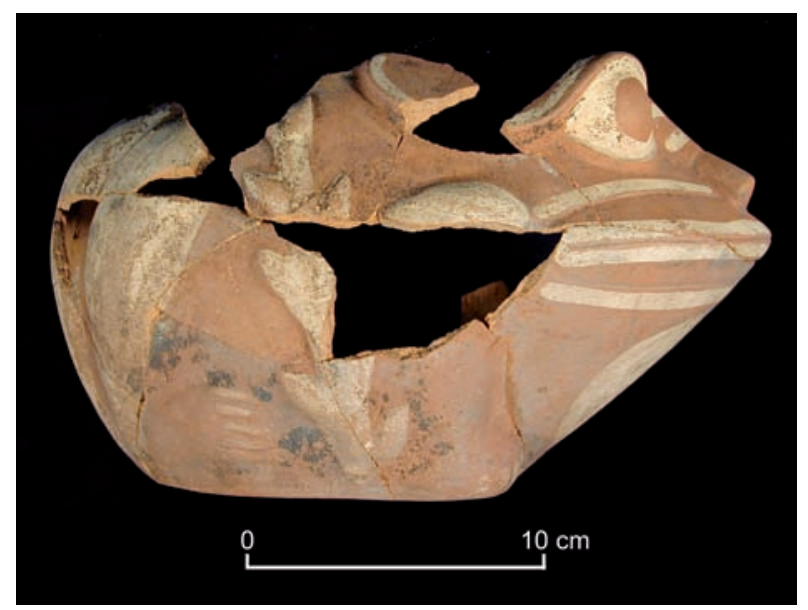

Figura 4. Vasija escultórica en forma de sapo de la fase Moche IV (Procedencia: Conjunto \#5 de la zona urbana del sitio Guadalupito).

Figure 4.Toad shape sculpted vessel of Moche IV phase (Proceeds from: Conjunto \#5 from the urban area of Guadalupito site).

La producción y distribución de cerámica es una parte de la economía moche que necesita más investigación y análisis detallado. Solo media decena de talleres de cerámica moche han sido excavados hasta la fecha. Pero en un territorio con 200 kilómetros de largo, la organización, tamaño y escala de la producción cerámica son aspectos que aún nos son esquivos. Talleres como los de Pampa Grande (Shimada 1994a) y Huacas de Moche (Uceda y Armas 1998; Bernier 2005) o de Cerro Mayal (Russell et al. 1994, 1998; Russell y Jackson 2001) podrían ser el tipo recurrente en los sitios urbanos y aldeanos como también pueden representar la excepción en la mayoría de ellos. Talleres corporativos de artesanos especialistas trabajando en proximidad a agentes gubernamentales en sitios residenciales urbanos, 
como también talleres familiares en localidades secundarias o rurales, son posibilidades distintas de la organización productiva alfarera moche y no debe descartarse su existencia contemporánea, pero en diferentes contextos socioeconómicos.

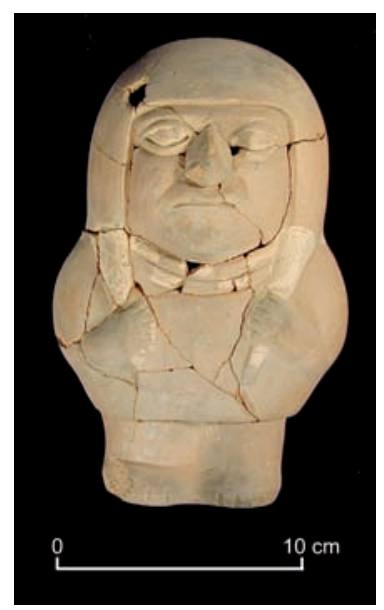

Figura 5. Figurina vacia en forma de mujer, fase Moche III (Procedencia: Tumba \#3 de la Terraza Norte del sitio El Castillo).

Figure 5. Female shaped emptied figurine, Moche III phase (Proceeds from: tomb \#3 from the Northern terrace of El Castillo site).

La producción de cerámica y la arqueología de las unidades domésticas -mediante la excavación en áreas de conjuntos residenciales- son aspectos de las sociedades complejas que en los últimos años han recibido mayor atención (Uceda y Armas 1997, 1998; Bernier 2005). Antes de iniciar nuestro proyecto había muy poca información sobre la producción de cerámica moche en el valle de Santa. Se asumía que la cerámica de mayor calidad se habría obtenido a través de los vínculos comerciales entre la capital y los nuevos centros que surgieron en el valle de Santa siempre y cuando la población moche fuese poco numerosa. Un aumento importante de la población moche en el valle de Santa habría provocado también un aumento significativo en la necesidad de cerámica moche. En tal sentido, la producción local de cerámica de estilo Moche para servir aspectos relacionados con los intereses políticos, económicos e ideológicos, así como aquellos de pertenencia étnica, era inevitable y probablemente debió desempeñar un rol muy importante en la construcción de la nueva sociedad provincial. 


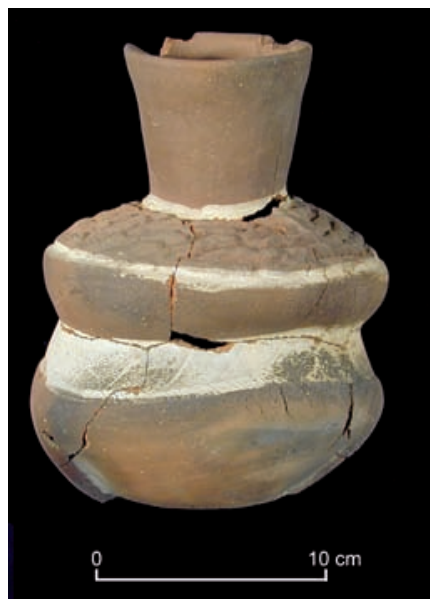

Figura. 6. Vasija escultórica de la fase Moche IV con el motivo de maní (Procedencia: cementerio al noroeste de la zona urbana del sitio Hacienda San José, Lacramarca).

Figure 6. Moche IV phase sculpted vessel with peanut motif (Proceeds from: Northwestern cemetery from the urban area of Hacienda San José site, Lacramarca).

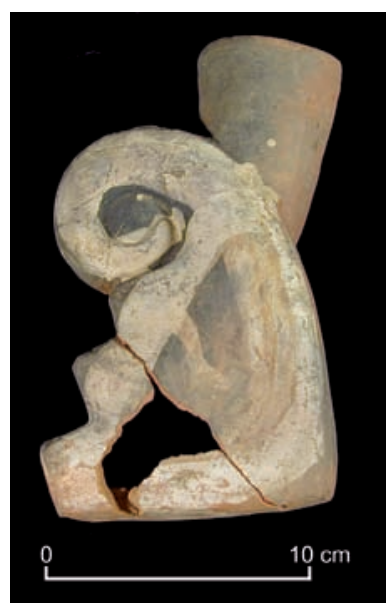

Figura 7. Vasija escultórica de la fase Moche III en forma de ola con el motivo de la escalera (Procedencia: Tumba \#3 de la Terraza Norte del sitio El Castillo).

Figure 7. Moche III phase wave-shaped sculpted vessel with ladder motif (Proceeds from: Tomb \#3 from the Northern Terrace of El Castillo site).

Con la finalidad de comprender la naturaleza de la presencia de Moche en el valle de Santa, debemos recalcar que se han identificado más de 205 sitios de esta cultura y que la cerámica constituye siempre la clase de 
objeto más abundante en estos establecimientos de diferentes tamaños y funciones (Donnan 1973; Wilson 1988; Chapdelaine et al. 2003).

$\mathrm{Si}$ asumimos que la presencia de moldes asociados a recipientes con defectos de cocción y a una gran cantidad de cerámica típica de Moche en sitios de habitación así como en cementerios son elementos suficientes para discutir sobre la producción de cerámica en estos mismos sitios o en los sitios vecinos, la existencia de varios centros de producción de cerámica en la parte baja del valle de Santa concuerda bien con el tamaño de la población moche en este valle y con sus necesidades para la utilización cotidiana de vasijas de cerámica y de otras categorías de artefactos de cerámica (Figura 8).

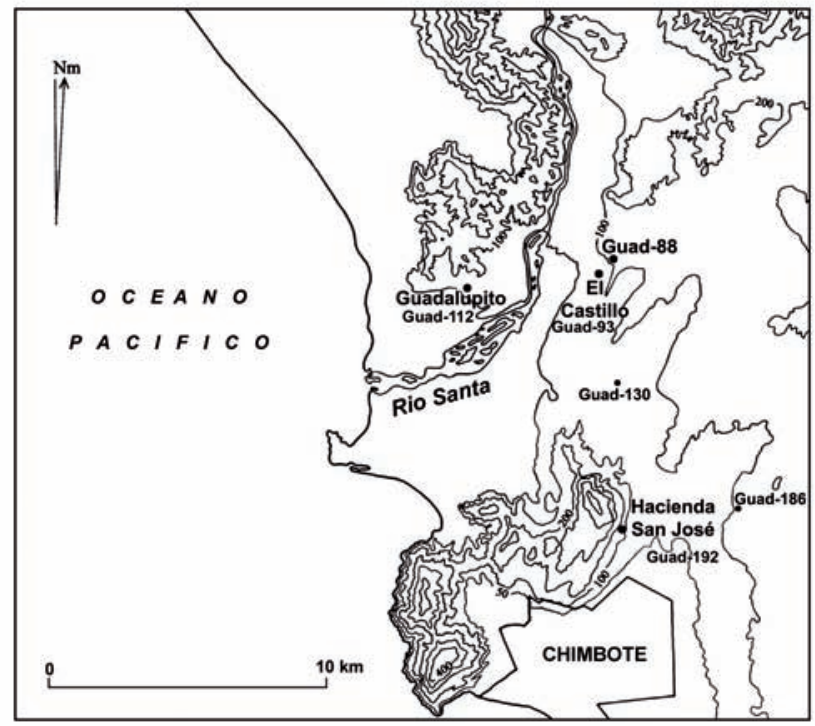

Figura 8. Localización de los sitios moche con moldes de la parte baja del valle de Santa.

Figure 8. Location of moche sites with molds in lower Santa valley.

Se había postulado que en el valle de Santa se produjo localmente cerámica moche, complementada con el intercambio y distribución de moldes (Donnan 1973; Wilson 1988). Sin embargo, sólo unos pocos moldes cerámicos fueron reportados antes del inicio de nuestras investigaciones en el valle de Santa. En el sitio Moche III El Castillo (Figura 9) se han encontrado fragmentos de moldes y platos de alfarero dentro de los rellenos de tierra y desechos entre los pisos de las construcciones en la Terraza Norte, que corresponde a un sector de carácter administrativo donde predomina un sistema de terrazas con patios, banquetas y rampas. También hemos hallado 
este tipo de indicios de producción cerámica en el sector denominado Terraza Este, donde se documentó un sector de arquitectura pública compuesto de una gran plaza y un sistema de banquetas que conduce hacia un trono. Hasta el momento este asentamiento constituiría el único sitio con evidencias indirectas de producción cerámica de la fase Moche III identificado en el valle de Santa (Chapdelaine y Pimentel 2001, 2002; Chapdelaine et al. 2003).

En el sitio Moche IV de Guadalupito, un centro urbano compuesto por conjuntos residenciales y administrativos, dos grandes plataformas de adobes, plazas extensas y cementerios, la presencia de moldes en superficie fue percibida como indicio de producción supervisada por las elites (Wilson 1988: 211). Durante nuestros trabajos del 2002 se recuperaron más moldes en las excavaciones de los conjuntos residenciales. Sin embargo, a pesar de las prospecciones intensivas y el levantamiento detallado de planimetría de la zona residencial, no se ubicó ningún probable taller o área de producción cerámica intensiva y especializada (Chapdelaine et al. 2003: 26-36).

El sitio Hacienda San José, localizado en el valle de Lacramarca, fue el segundo asentamiento Moche IV que permitió iniciar la comprensión de una producción local extensiva de cerámica (Figuras 8, 10). En este sitio, compuesto por conjuntos residenciales, cementerios y un edificio platafórmico pequeńo, efectuamos recolecciones sistemáticas durante dos temporadas y realizamos excavaciones en área durante una temporada, sin que hallemos un taller de producción cerámica. Sin embargo, documentamos 135 moldes completos o fragmentados y varios fragmentos de vasijas de cerámica con defectos de cocción (agrietamiento y/o deformación de las paredes de cámaras y golletes), asociados a cuatro conjuntos habitacionales (Chapdelaine y Pimentel 2001, 2002). Gran parte de estos materiales fueron recuperados sobre los pisos de barro y en los rellenos de tierra y desechos bajo los pisos de ambientes y patios al interior de los conjuntos. En el Conjunto \#4 no se definió un área para quema de vasijas, pero sí un ambiente (Ambiente \#9) con adobes dispersos fuertemente calcinados, pedazos de arcilla cruda y abundantes fragmentos de vasijas domésticas, sin mayores evidencias de una cadena operativa de producción alfarera (Chapdelaine y Pimentel 2002: 112, Figura 35).

Más moldes fueron hallados en los sitios GUAD-88 (Figura 11), GUAD-130 (Figura 12) y GUAD-186. Estos sitios están localizados en los alrededores de El Castillo y están asociados a la ocupación Moche IV, mientras que El Castillo corresponde a la fase Moche III. En estos nuevos 
asentamientos de la fase IV y particularmente en GUAD-88 encontramos fragmentos de más de ochenta moldes para la fabricación de cántaros llanos, cántaros con cara-gollete, botellas escultóricas, figurinas y aplicaciones (Taillon-Pellerin 2004).

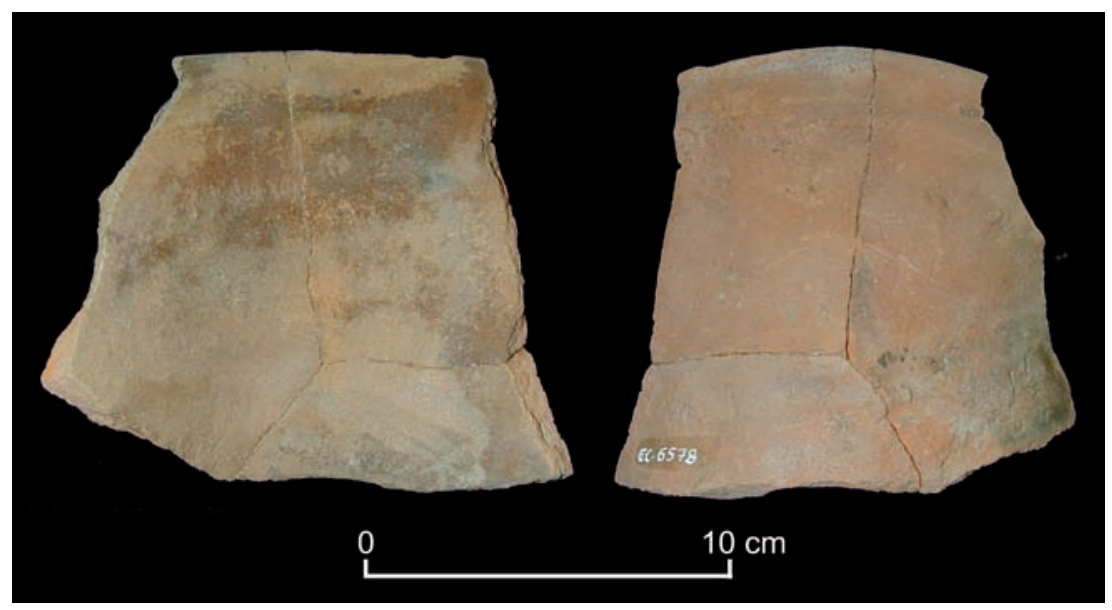

Figura 9. Molde de un florero, fase Moche III (Procedencia: Terraza Norte del sitio El Castillo).

Figure 9. Vase mold, Moche III phase (Proceeds from: Northern Terrace of El Castillo site).

Un porcentaje significativo de la cerámica moche de Santa habría sido producida localmente como respuesta a un crecimiento demográfico interno y a la necesidad utilizar cotidianamente y en eventos especiales vasijas y otros artefactos cerámicos. La utilización de moldes para reproducir tendencias estilísticas populares en los principales sitios de los valles de Moche y Chicama pudo devenir en un medio para la reproducción constante de modelos originales, que implicó la complejización del sistema de producción inherente a la elaboración de cerámica por moldeado, pero que también significó el desarrollo de un nivel de conocimiento y manipulación del simbolismo de las imágenes en ella representadas (Cummins 1994, 1998: 208-210). Siguiendo esta perspectiva, es muy posible que los artesanos especialistas en la fabricación de las vasijas por moldeado hayan sido inmigrantes originarios de los valles centrales de la civilización Moche. Pero es necesario preguntarnos si en esta producción cerámica especializada participaron también artesanos que pertenecían a los grupos étnicos locales de filiación gallinazo. 


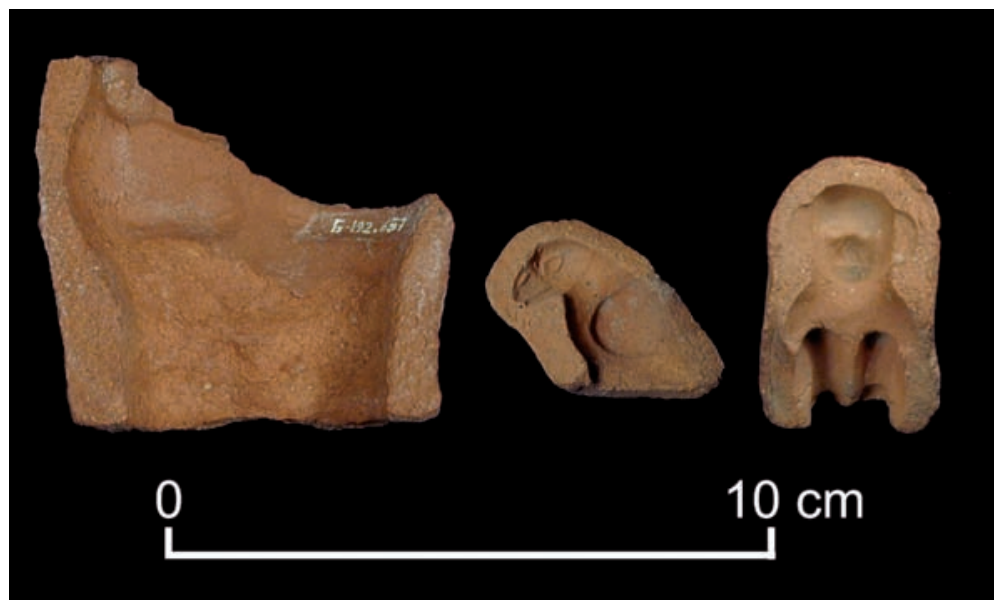

Figura 10. Moldes de la fase Moche IV del sitio Hacienda San José, Lacramarca.

Figure 10. Moche IV phase molds from Hacienda San José site, Lacramarca.

El contexto geopolítico de procedencia de la cerámica moche habría tenido un impacto directo sobre su distribución. Si la producción cerámica hubiese sido controlada por dirigentes de otros valles y sus representantes en el valle de Santa, la distribución de piezas se habría limitado a las elites moche y locales que habrían recibido vasijas finas a manera de presentes. Por el contrario, si la cerámica fue elaborada localmente en talleres de variado tamańo y localizados en diferentes sitios del valle, mayores segmentos socioeconómicos pudieron tener acceso a estos artefactos con fines domésticos, ceremoniales y funerarios. Ciertamente los datos para los sitios Guadalupito, Hacienda San José y GUAD-88 de la fase Moche IV no se adecuan a la hipótesis de un fuerte control estatal de la producción cerámica o una centralización física de la misma. Los datos arqueológicos más bien sugieren una diversificación de los centros de producción cerámica moche en el valle de Santa. 


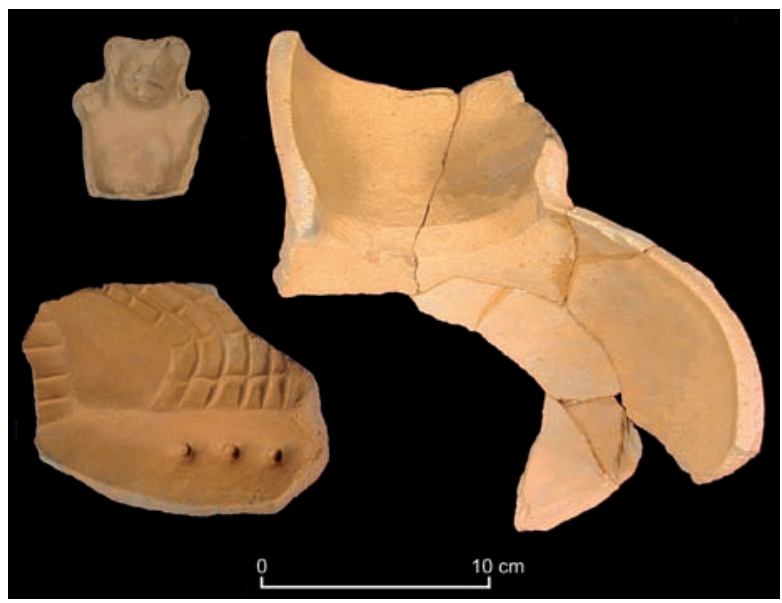

Figura 11. Moldes de la fase Moche IV del sitio GUAD-88.

Figure 11. Moche IV phase molds from GUAD-88 site.

\section{EL ORIGEN DE LA CERÁMICA MOCHE: CONTRIBUCIÓN DEL ANÁLISIS POR ACTIVACIÓN NEUTRÓNICA}

Generalmente la técnica popular para identificar la procedencia de un tipo particular de artefacto es el criterio de abundancia. En nuestro caso, la impresionante cantidad de artefactos moche en el valle de Santa era y se considera todavía como la evidencia principal para argüir sobre la presencia física de los moches en este valle. Más de 205 sitios han sido identificados como pertenecientes a la cultura Moche o que presentan un componente moche y la mayoría de ellos localizados en la parte baja del valle. Varios cementerios ricos en cerámica pintada o moldeada típica del estilo Moche están asociados con sitios de habitación. Este es un elemento de base para poder asumir que los moches ocuparon físicamente el valle de Santa y que el comercio y la difusión no explican la presencia de colecciones abundantes y diversificadas de objetos de estilo Moche. Los artefactos de cerámica, metal, piedra, textil, conchas y madera, así como los restos arquitectónicos y los contextos funerarios son todos atribuibles a la cultura Moche. La circulación y distribución de productos cerámicos entre los valles de Moche y de Santa no puede ser eliminada, pero parece imposible que estas actividades expliquen por sí solas la gran cantidad de vasijas implicadas que se encuentran en el valle de Santa. La distribución local de los artefactos de estilo Moche manufacturados localmente debe ser entonces la opción lógica para explicar su presencia en el valle de Santa. 
El origen o la proveniencia de un artefacto constituyen un criterio predominante para discutir sobre la distribución y la producción de la cerámica. La imitación de un producto es siempre una posibilidad y la identificación visual de una vasija pintada o moldeada como típica del estilo Moche estará basada en la capacidad del analista y en la validez del concepto de definición de qué es la cerámica típica Moche. En cualquier producción artesanal, la calidad variará y la dificultad de dar una identificación cultural específica se convertirá en un desafío más difícil de resolver.

Además de trabajar con esquemas mentales y una buena colección de referencia -lo cual es fácil de hacer con la cerámica moche- los arqueólogos disponen de varias técnicas o métodos para la identificación cultural de la cerámica. Primero, el análisis tecnológico y en particular el análisis de la pasta, que pueden dar más peso a las variables morfo-estilísticas, en particular datos mineralógicos obtenidos del análisis de secciones delgadas. En segundo lugar, el análisis por activación neutrónica o técnicas similares que se utilizan regularmente para estudiar la procedencia de cualquier conjunto de cerámica. Hemos utilizado este método y a continuación presentamos brevemente los resultados del análisis de 34 muestras de cerámica, una pequeña muestra para estudiar la procedencia de artefactos de cerámica moche en el valle de Santa (Tabla 1). En El Castillo se seleccionaron 11 muestras, 6 muestras en Guadalupito y 16 muestras provienen de Hacienda San José. Cada muestra implicaba la manipulación de 100 miligramos de peso para ser sometida al reactor de la Escuela Politécnica de Montreal (Kennedy y Chapdelaine 2004). El análisis comprendió moldes, botellas, floreros, cántaros y cuencos. Además se sometieron 4 muestras de arcilla cruda y de adobes (todas del sitio Hacienda San José, con excepción de una arcilla cruda tomada en un corte del río Santa, 2 kilómetros al este de Guadalupito y 3 kilómetros al oeste de El Castillo) que fueron examinadas paralelamente, y que pueden a su vez ser comparadas con los datos del sitio Huacas de Moche (Chapdelaine et al. 1995) para entender la relación entre los valles de Moche y Santa.

Los resultados expresados en partes por millón de cada elemento químico identificado fueron comparados entre las muestras para determinar su distancia; cuanto más grande es el número, más grande es la diferencia que identifica una arcilla distinta. Una manera de ilustrar esta comparación es el dendrograma que permite agregar las muestras más parecidas o similares. Examinando el dendrograma (Figura 13) se puede observar cinco grupos de diferentes tamaños. Las distancias más pequeñas expresan una fuerte posibilidad de provenir de la misma fuente de arcilla o de la misma pasta preparada. 


\begin{tabular}{|c|c|c|c|c|c|}
\hline No. & No cat. & Sitio & Fase & Descripción & Contexto* \\
\hline PE301 & G-112.898 & Guadalupito & IV & Florero, motivo ave & $\mathrm{CA \# 4} ; \mathrm{A}-1$ \\
\hline PE302 & G-112.3637 & Guadalupito & IV & Florero, motivo flor & CA\#5; $\mathrm{A}-3$, nicho 3 \\
\hline PE303 & G-112.4576 & Guadalupito & IV & Cántaro, motivo cangrejo & 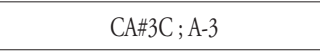 \\
\hline PE304 & G-112.27 & Guadalupito & IV & Fragmento de molde & superficie, $C A \# 2-3$ \\
\hline PE305 & G-112.34 & Guadalupito & IV & Fragmento de molde & superficie, $C A \# 2-3$ \\
\hline PE306 & G-97 & $\begin{array}{l}\text { Guadalupito sector, } \\
\text { Rio Santa }\end{array}$ & --- & Arcilla natural & cerca G-97 \\
\hline PE307 & EC-5935 & El Castillo Norte & III & Botella, dios con colmillos & $\mathrm{CA} \# 2, \mathrm{~A}-2 \mathrm{~S}$ \\
\hline PE308 & EC-5981 & El Castillo Norte & III & Botella, monstros & $\mathrm{CA} \# 2$, tumba $\# 2$ \\
\hline PE309 & EC-5985 & El Castillo Norte & III & Botella, motivo sol & $\mathrm{CA} \# 2$, tumba $\# 2$ \\
\hline PE310 & EC-6466 & El Castillo Norte & III & Botella, achira con ratón & $\mathrm{CA} \# 2$, tumba $\# 3$ \\
\hline PE311 & EC-6469 & El Castillo Norte & III & Botella, motivo ave & $\mathrm{CA} \# 2$, tumba $\# 3$ \\
\hline PE312 & EC-5950 & El Castillo Norte & III & Fragmento de molde & $\mathrm{CA} \# 2 ; \mathrm{A}-2 \mathrm{~S}$ \\
\hline PE313 & ECE-696 & El Castillo Este & III & Botella, dios con colmillos & $\mathrm{CA} 2$ \\
\hline PE314 & ECE-773 & El Castillo Este & III & Fragmento de molde & $\mathrm{CA} \# 2, \mathrm{~A}-5$ \\
\hline PE315 & ECE-1564 & El Castillo Este & III & Florero crudo & $\mathrm{CA} \# 2 ; \mathrm{A}-5$ \\
\hline PE316 & ECE-1771 & El Castillo Este & III & Crisol & $\mathrm{CA \# 2;A-5}$ \\
\hline PE317 & ECE-2588 & El Castillo Este & III & Tiesto Gallinazo crudo & Terraza alta, cuadro L5 \\
\hline PE318 & G-88 & Guad- 88 & IV? & Tiesto Moche crudo & Sector Este, p.h. \#3 \\
\hline PE319 & G-192-187S & Hacienda San José & --- & Arcilla cruda modelada & Sector Sur \\
\hline PE320 & G-192-J29 & Hacienda San José & $-\cdots$ & Desecho arcilla cruda & Sector central, CA\#4; A-9A \\
\hline PE321 & G-192-A & Hacienda San José & $-\cdots$ & Adobe quemada & Sector Sur \\
\hline PE322 & G-192-G16 & Hacienda San José & --- & Fragmento adobe & Sector Norte, CA\#1, A-1 \\
\hline PE323 & G-192-1651 & Hacienda San José & IV & Huaco retrato & Sector central, CA\#4 ; A-6 \\
\hline $\begin{array}{c}\text { PE324 G-192- } \\
1534\end{array}$ & $\begin{array}{l}\text { Hacienda } \\
\text { San José }\end{array}$ & IV & $\begin{array}{l}\text { Fragmento } \\
\text { de molde }\end{array}$ & Sector Norte, CA\#2, A-4 & \\
\hline $\begin{array}{c}\text { PE325 G-192- } \\
2631\end{array}$ & $\begin{array}{l}\text { Hacienda } \\
\text { San José }\end{array}$ & IV & $\begin{array}{l}\text { Fragmento } \\
\text { de molde }\end{array}$ & Sector central, CA\#4; superficie & \\
\hline PE326 & G-192-2644 & Hacienda San José & IV & Fragmento figurina & Sector central, CA\#4;A-5A \\
\hline PE327 & G-192-2645 & Hacienda San José & IV & Fragmento figurina-silbato & Sector central, CA\#4 ; A-5A \\
\hline PE328 & G-192-338 & Hacienda San José & IV & Florero, motivo triángulo & Sector Norte, cuadro H-16, tumba \\
\hline PE329 & G-192-410 & Hacienda San José & IV & Florero, motivo geométrico & Sector Norte, cuadro H-20 \\
\hline PE330 & G-192-1040 & Hacienda San José & IV & Florero, motivo geométrico & Sector Sur, superficie \\
\hline PE331 & G-192-926 & Hacienda San José & IV & Plato, motivo geométrico & Sector Norte, cuadro G-17, superficie \\
\hline PE332 & G-192-210 & Hacienda San José & IV & Plato, motivo geométrico & Sector Norte, cuadro H-18, superficie \\
\hline PE333 & G-192-317 & Hacienda San José & IV & Cántaro, exterior blanco & Sector Norte, cuadro H-18, superficie \\
\hline PE334 & G-192-328 & Hacienda San José & IV & Cántaro, motivo línea blanca & Sector Norte, cuadro H-18, superficie \\
\hline
\end{tabular}

* CA: conjunto arquitectónico; A-: ambiente; p.h.: pozo de huaquero; cuadro: unidad de registro de 20 x 20 metros.

\section{Tabla 1. Lista de las muestras analizadas con el método de activación neutrónica.}

Table 1. Analysed samples with neutron activation method. 


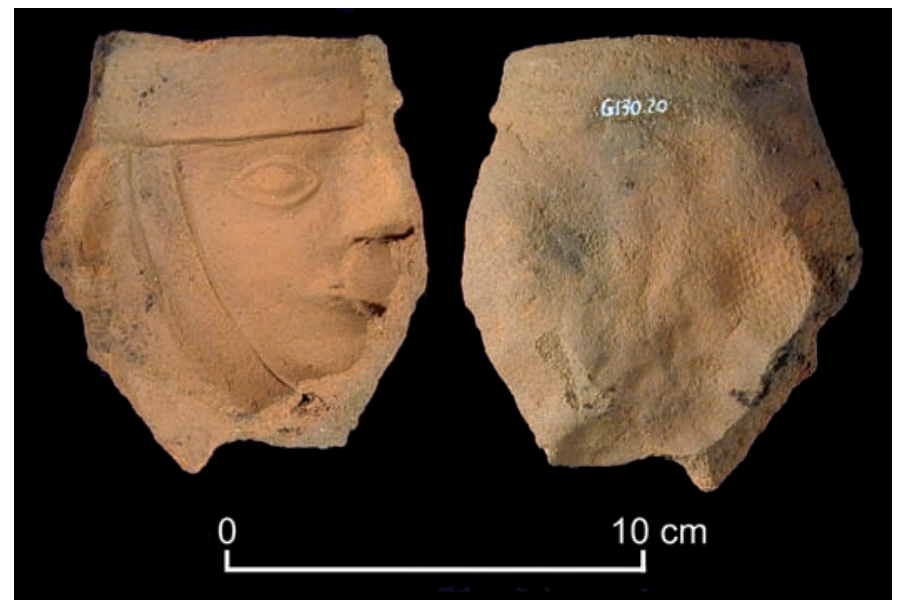

Figura 12. Molde de la fase Moche IV del sitio GUAD-130.

Figure 12. Moche IV phase mold from GUAD-130 site.

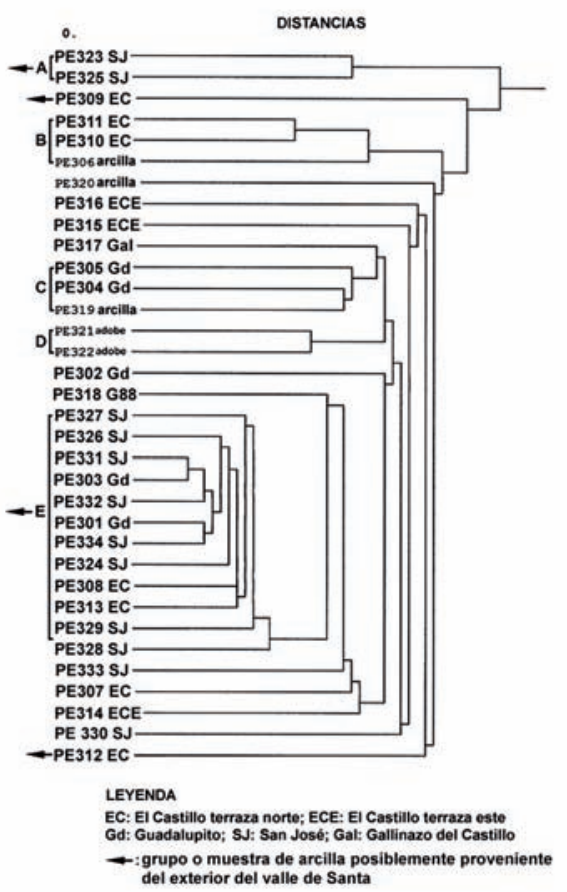

25.

14.10
21.20

19.88

11.89

11.89

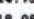

0.00

$(7.46$

16.74

16.49

15.18

14.11

13.89

15.36

12.58

12.58

15.70

15.62

3.79

0.74

9.38

9.21
9.13

9.33

9.12

9.78

9.78

9.03

9.90
10.83

2.03

4.31

14.38

14.53

16.05

17.23

Figura 13. Dendrograma de 34 muestras del valle de Santa analizadas por el método de activación neutrónica.

Figure 13. Dendrogram of 34 samples from Santa valley analyzed by neutron activation method.

Se puede observar que el Grupo A es minoritario, con dos muestras, y parece distinto tanto de las muestras de arcilla natural del valle de Santa como de la mayor parte de muestras de cerámica santeńa, pudiendo corresponder a piezas 
importadas de otro valle o elaboradas con una fuente local distinta de arcilla. La muestra Pe-323 corresponde a una vasija retrato de muy buena calidad del Conjunto \#4 del sitio San José (Figura 14).

Los grupos B, C y D son considerados como objetos de producción local, apoyándonos en la similitud o la distancia corta que existe entre las muestras de algunas vasijas con las muestras de arcilla local. Estos grupos son minoritarios, indicando sin duda que las arcillas naturales analizadas no fueron muy populares en la producción de otras vasijas seleccionadas del valle de Santa. El Grupo D está constituido por muestras de dos adobes de Hacienda San José y podemos sostener de manera preliminar que este tipo de arcilla cruda no fue utilizado por los alfareros. Sin embargo, no se puede excluir totalmente este tipo de arcilla si consideramos que las vasijas fueron fabricadas con una pasta preparada y mezclada con diferentes tipos de arcilla.

El Grupo E es el más extenso, pero su correlación con las arcillas locales analizadas es problemática. Las once muestras presentan una gran similitud y el grupo parece homogéneo (Figura 15). No se puede eliminar la posibilidad de un origen en el valle de Santa pero como las distancias entre este grupo y las muestras que han sido consideradas locales son fuertes, creemos que es importante comparar este grupo con los datos que tenemos del sitio Huacas de Moche. Al mismo tiempo se puede examinar la posición del Grupo A así como de las muestras Pe-309 y Pe-312, que corresponden a un fragmento de botella con el motivo del sol radiante proveniente de una tumba de elite del sitio El Castillo y a un molde de vasija escultórica, respectivamente, para así determinar el posible origen de estas piezas, tan distintas de las muestras asociadas a un origen local, es decir los grupos B, C y D.

Se ha determinado de manera muy clara que las muestras del Grupo E no tienen correspondencia clara con las muestras del sitio Huacas de Moche (Figura 17, y ver Kennedy y Chapdelaine 2004; para otros dendrogramas en las Figuras 4 y 5 disponibles en el sitio http://www.anthro.umontreal. ca/varia/colloque_SAA_4/SAA04/index.html). Este grupo se mantiene homogéneo pero las distancias entre ciertos miembros del Grupo E son más parecidas a las muestras de Huacas de Moche que a las del valle de Santa. Dentro de esta perspectiva, podemos mantener la idea de que las muestras proceden del valle de Moche o que en su fabricación se utilizó una pasta no muy diferente de la pasta utilizada en la fabricación de figurinas y cerámica decorada del sitio Huacas de Moche. 


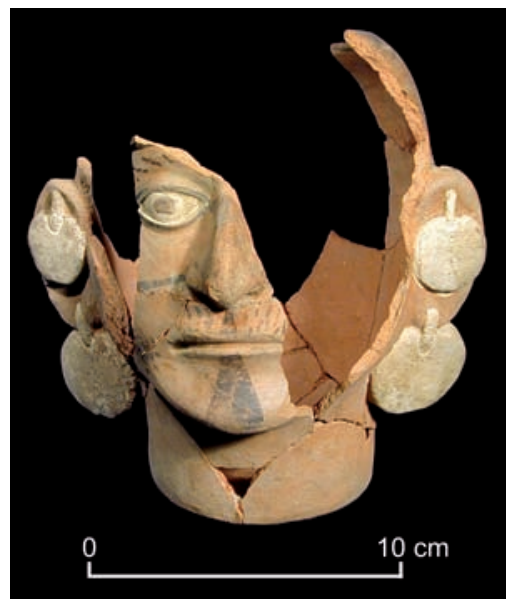

Figura 14. Vasija tipo «huaco retrato» del grupo A, fase Moche IV

(Procedencia: Conjunto \#4 del sitio Hacienda San José, Lacramarca).

Figure 14. "Huaco retrato" vessel type from group A, Moche IV phase (Proceeds from:

Conjunto \#4 of Hacienda San José site, Lacramarca).

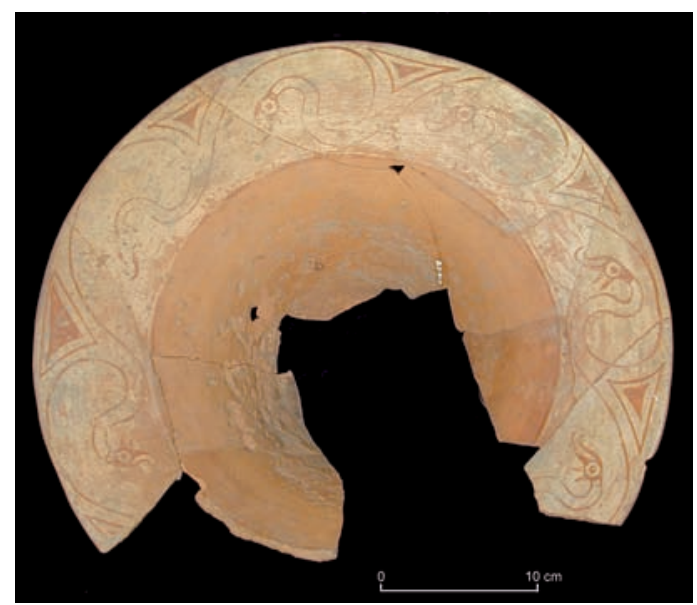

Figura 15. Florero de la fase Moche IV con un motivo de cabezas de ave

(Procedencia: Conjunto \#4 de la zona urbana del sitio Guadalupito).

Figure 15. Moche IV phase vase with bird head motif (Proceeds from Conjunto \#4 of the urban zone of Guadalupito site).

El Grupo A y las muestras Pe-309 y Pe-312 no tienen una relación con las arcillas, las figurinas y la cerámica decorada del sitio Huacas de Moche (Kennedy y Chapdelaine 2004: Figuras 3, 4, 5). La conclusión más lógica sería entonces considerar un origen desconocido de estas muestras, lo cual sugiere también una diversidad de fuentes de arcilla en la producción alfarera del valle de Santa durante la presencia moche. Un resultado inequívoco 
corresponde a la muestra Pe-302 que no forma parte de los grupos identificados pero cuya distancia con las muestras del Grupo E no es grande. Se trata de un florero (Figura 16) elaborado con pasta de alta calidad, hallado en el Conjunto \#5 de Guadalupito, que está ubicado frente a la plataforma principal de este centro urbano. Esta muestra presentó una composición similar a las vasijas finas, figurinas y arcillas analizadas en el sitio Huacas de Moche y podemos asumir que esta pieza fue elaborada en el valle de Moche y llevada al valle de Santa como un artículo de alto status. Adicionalmente, debemos señalar que este florero presenta una decoración en línea fina ejecutada con gran maestría y debe formar parte de la producción de un artesano afiliado a un taller prestigioso de pintores de alfarería ritual.

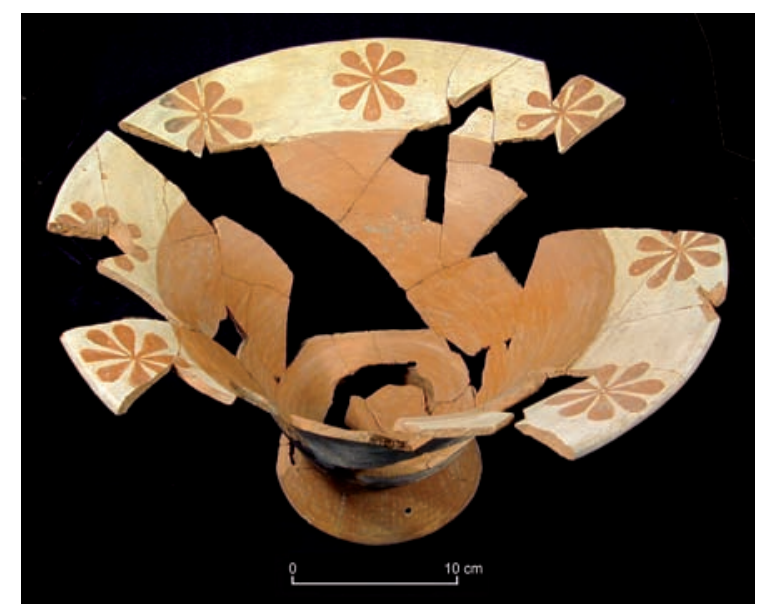

Figura 16. Florero de la fase Moche IV con un motivo floral (Procedencia: nicho del Conjunto \#5 de la zona urbana del sitio Guadalupito).

Figure 16. Moche IV phase vase with flower motif (Proceeds from: Conjunto \#5 niche of the urban zone of Guadalupito site).

Al comparar la composición química de las muestras de arcillas de los valles de Santa y de Moche surgió un primer resultado. Las arcillas recolectadas en depósitos sedimentarios del valle de Santa muestran una composición similar en su conjunto, pero difieren de las arcillas y las piezas de Huacas de Moche. También existió una notoria distancia entre las vasijas de Huacas de Moche y la mayoría de las muestras analizadas provenientes del valle de Santa (Figura 17). 


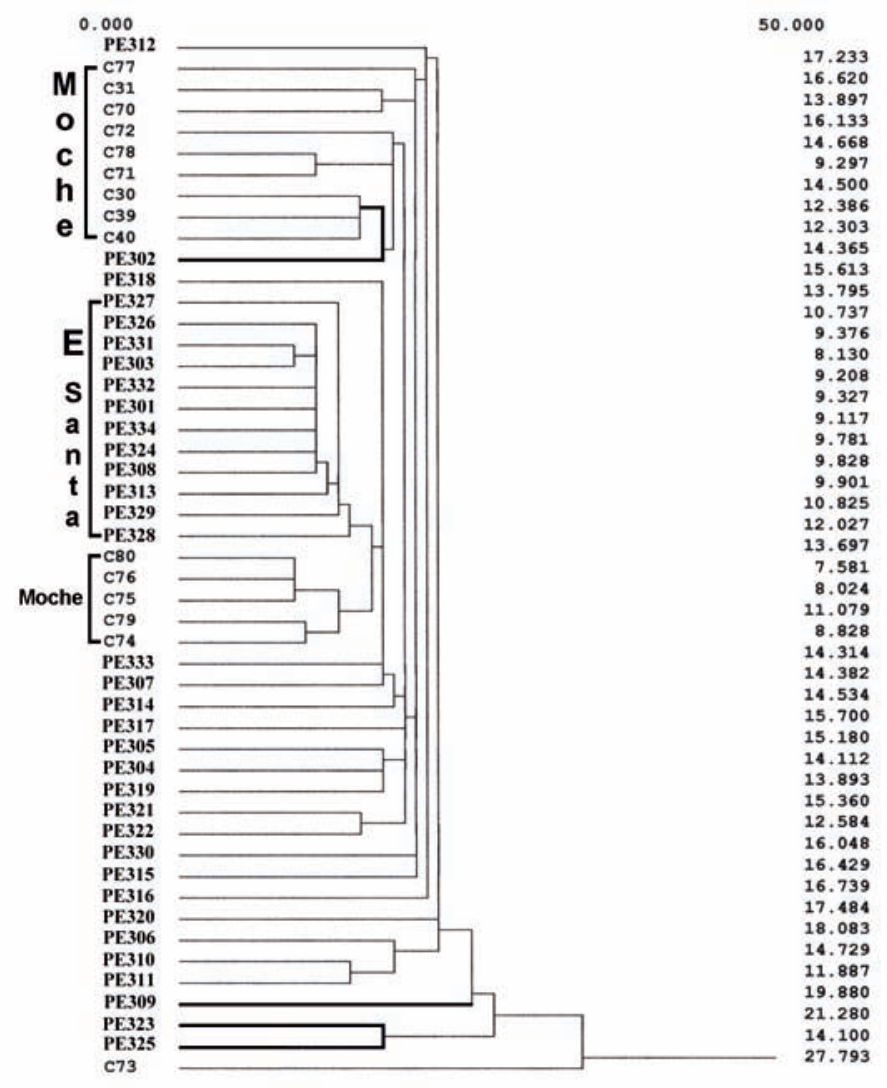

Figura 17. Dendrograma comparativo de las muestras del valle de Santa y Huacas de Moche.

Figure 17. Comparative dendrogram of Santa valley and Huacas de Moche samples.

El resultado del análisis de pastas por activación neutrónica ha sido alentador, particularmente al relacionarlo con los datos proporcionados por este mismo procedimiento en el sitio Huacas de Moche. Permite asumir con mayores evidencias la existencia de una producción local de redes de intercambio de cerámica fina entre el valle de Santa con otros valles de la Costa Norte. Pero para llegar a formular un cuadro más completo sobre estos aspectos de la producción alfarera debemos ampliar el número de piezas analizadas, incluyendo un mayor número de vasijas llanas y de uso doméstico. 


\section{CONCLUSIOnes}

Dentro de un marco histórico de cuatro siglos de duración, durante el cual se fue construyendo una nueva sociedad regional que reprodujo muy de cerca la organización de la sociedad de origen, cada comunidad moche en el valle de Santa fue económicamente autosuficiente. Tuvieron que generar excedentes para los señores locales moche y para sus linajes originales de los valles más al norte.

Basados en las sorprendentes semejanzas de todos los aspectos de la cultura de Moche y los resultados del Proyecto Santa de la Universidad de Montreal, podemos sostener la idea que el valle de Santa constituyó una provincia moche controlada por un gobierno directo y que Guadalupito fue el centro político y económico de la provincia de Santa durante la fase IV. Sin embargo, la cerámica moche del valle de Santa muestra tendencias distintas, que aunque menores, pueden ser calificadas como indicadores de un estilo Santa dentro del estilo general Moche, una suerte de Moche Provincial. Este desarrollo podría eventualmente haber conducido a una independencia o autonomía local respecto del centro moche, pero los fuertes lazos fueron más poderosos que las diferencias. El valle de Santa se entiende todavía como la periferia del corazón moche y queda demostrado que los datos de la cerámica pueden ser utilizados para hacer inferencias sobre cuestiones políticas complejas. Se necesitan otras evidencias para completar la interpretación sobre el rol de la cerámica, pero persiste la idea de que esta nos proporciona elementos valiosos para comprender el proceso social involucrado en su fabricación, distribución y accesibilidad, ya sea limitada a un grupo reducido de miembros de la sociedad o disponible a grandes segmentos de la población.

El desarrollo de un estilo provincial Moche en el valle de Santa puede ser interpretado como evidencia de la autonomía política de los gobernantes moche en este valle (Figura 18). Sin embargo, consideramos que las relaciones constantes entre el corazón y la periferia explican mejor las semejanzas generales de la producción cultural de los valles de Moche y Santa. La conclusión sería que los gobernantes de los valles centrales de Moche controlaron directamente la población de Santa. Será interesante en el futuro comprobar si este tipo de gobierno político existió en el centro regional Pañamarca del valle de Nepeña, donde más datos sobre la presencia de Moche proporcionarán mayores luces sobre la organización política del Estado Moche Sur en esta zona fronteriza. 
Al nivel estilístico los lazos entre los valles de Santa y Moche durante las fases Moche III y IV (aproximadamente 350-800 d.C.) eran más fuertes que las fuerzas centrífugas. La ocurrencia de tendencias localistas no es improbable, tanto en elites como en segmentos poblacionales de menor status ocupando el valle de Santa por generaciones sucesivas. Pero la cultura material de las fases Moche III y IV en este valle y particularmente la cerámica y su carga simbólica indican estrechos vínculos entre ambos valles, tanto en la producción como en el empleo de artículos de alto valor económico y simbólico, como en los artefactos de producción y consumo masivo. Durante la larga ocupación moche del valle de Santa parece lógico pensar que los moches nacidos en este valle se volvieron "santeños» más que «mochicas» y que por lo tanto el desarrollo de una identidad provincial moche era inevitable, especialmente para los miembros de las clases populares que tenían pocas posibilidades de regresar a su tierra de origen.

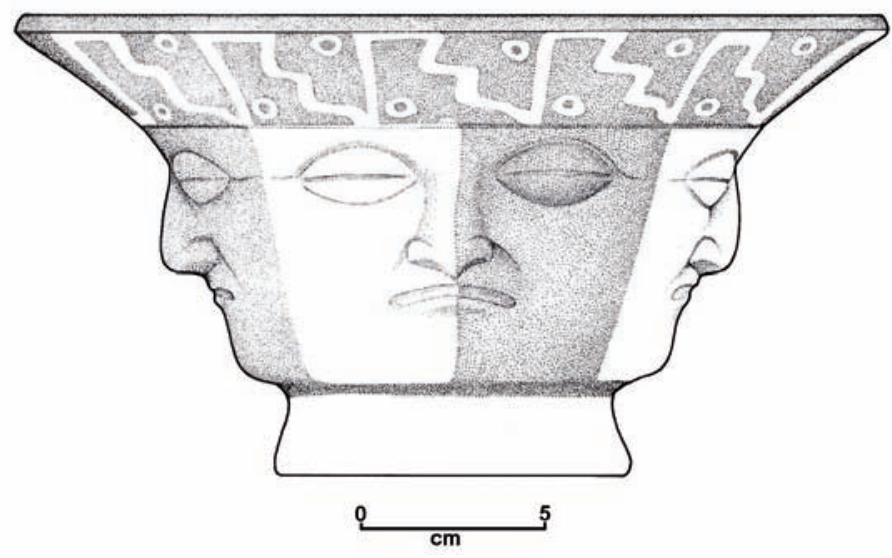

Figura 18. Reconstitución de un florero pedestal de la fase Moche III con representación escultórica de cuatro rostros humanos. Esta pieza representaria una variante estilistica local, con uso de pintura crema sobre rojo y ojos "grano de café" (Procedencia: Conjunto \#1 de la Terraza Norte del sitio El Castillo). Figure 18. Reconstitución Reassembly of a Moche III phase pedestal vase with the sculpted representation of four human faces. This piece represents a local stylistic variant with cream over red paint and "coffee grained" eyes (Proceeds from: Conjunto \#1 of the Northern Terrace of El Castillo site).

Es factible que los gobernantes de Huacas de Moche y de los centros asociados como El Brujo planificaran, consolidaran y ampliaran sus vínculos con el valle de Santa, introduciendo inicialmente en este valle sus propios 
referentes culturales y reproduciendo estructuras sociopolíticas e ideológicas vigentes desde la fase Moche III en el sitio El Castillo, con una reorientación notable de las estrategias de dominación durante la fase Moche IV, que significó la ampliación de la frontera agrícola y la creación de un nuevo centro de actividades ceremoniales y gubernamentales con sede en Guadalupito. El control de una población por otra puede incluir una primera etapa de demandas unilaterales por parte de los grupos dominantes sobre los dominados, con una fase ulterior de coexistencia negociada e interdependencia. Pero la presencia moche en el valle de Santa pudo implicar un proceso inverso, con coexistencia temprana seguida por una reformulación de los objetivos políticos y la estructura de las jerarquías sociales regionales.

La información arqueológica permite argumentar que la alta densidad de cerámica Moche IV en Santa fue el resultado de una producción local diversificada en ubicación de centros de manufactura, incluyendo la importación desde valles vecinos de piezas de alta calidad y posiblemente de moldes. La producción masiva y el acceso a moldes y vasijas de diferente calidad por diversos segmentos de las poblaciones en el valle de Santa son elementos que favorecen la idea de una promoción del estilo cerámico Moche -particularmente durante la fase IV- entre elites y las colectividades inmigrantes moche, como también con los nativos aculturados o con individuos que compartían intereses con los moches y que estuvieron involucrados en proyectos estatales como el desarrollo de la irrigación en el valle de Lacramarca y la emergencia de Guadalupito. Este proceso implicó complejos vínculos de cohesión social y redes de intercambio económico, que en conjunto permitieron la producción y circulación constante de piezas cerámicas y su consumo cotidiano. La definición de estos vínculos será un reto en los próximos años

La producción de cerámica moche en el valle de Santa y una factible red de distribución intravalle de la cerámica decorada jugaron un rol principal en la afirmación sociopolítica de una entidad Moche Santeña. La cerámica moche moldeada, pintada o llana fue empleada por los gobernantes, los líderes de los linajes o las asociaciones corporativas así como por el resto de las comunidades asentadas en la parte baja del valle de Santa y contribuyó durante varias generaciones tanto a la afirmación de su identidad frente a las poblaciones foráneas vecinas, como a una integración en los eventos y procesos norcosteños del Período Intermedio Temprano.

Para terminar, podemos concluir señalando que la cerámica moche del valle de Santa jugó un papel similar al que tuvo en el valle de Moche y 
que fue utilizada como herramienta ideológica e incentivo político y económico para cualquier individuo o grupo familiar que compartía los mismos valores que la elite moche. La producción masiva de cerámica local Moche de Santa y la amplia red de distribución dirigida hacia cada miembro de esta nueva sociedad regional moche desempeñaron un rol importante en la afirmación social y política de sus usuarios. Las mejores vasijas fueron hechas para los gobernantes, pero la producción y distribución de vasijas típicas moche fue también eficiente entre los miembros de las clases populares moche que ocupaban la parte baja del valle de Santa. Como nota final podemos afirmar que los moches no solamente propagaron la palabra de su poder sino que también pusieron a la disposición su exquisita y distintiva cerámica caracterizada por su bicromía y su alto grado de realismo.

Agradecimientos: Los autores desean expresar su agradecimiento a todos los miembros del Proyecto Santa de la Universidad de Montreal entre los años 2000 y 2004, en particular a Hélène Bernier, Véronique Bélisle, David Chicoine, France-Éliane Dumais, Julie Fournier, Juan López Marchena, Delicia Regalado y Alexandra Taillon-Pellerin. Asimismo a los organizadores del IV Seminario de Arqueología de la Universidad Nacional Federico Villarreal por brindar la oportunidad de exponer nuevos datos sobre la ocupación moche del valle de Santa.

\section{Notas}

El Proyecto Santa de la Universidad de Montreal es un programa de investigaciones arqueológicas auspiciado por el Consejo de Investigaciones en Ciencias Humanas del gobierno del Canadá. Los trabajos de campo de la primera fase fueron conducidos entre los años 2000 y 2002. Los trabajos de laboratorio se realizaron durante el 2003 y 2004. La segunda fase de este programa de investigaciones se ha iniciado en noviembre del 2005 y los objetivos de la investigación son básicamente las mismos: la excavación de los sitios importantes moche para entender la naturaleza de la provincia de Santa en el marco del Estado expansionista Moche Sur y la excavación en pequeña escala de sitios de filiación cultural Gallinazo para medir el impacto de la presencia moche en los grupos locales. La comprensión de las actividades domésticas y el fechado de los componentes más importantes y los principales eventos en estos sitios son otros de los objetivos fundamentales de nuestro proyecto.

\section{BibliografíA}

Arkush, E. N. y M. W. Allen. 2006. The Archaeology of Warfare, Prehistories of Raiding and Conquest. University Press of Florida, Gainesville.

Arkush, E. N. y C. Stanish. 2005. "Interpreting Conflict in the Ancient Andes: Implications for the Archaeology of Warfare". Current Anthropology 46 (1): 3-28. 
Arnold, D. E. 1993. Ecology and Ceramic Production in an Andean Community. Cambridge University Press, Londres.

Bawden, G. 1994. "La Paradoja Estructural: la Cultura Moche como Ideología Política”. En Moche: Propuestas y Perspectivas, editado por S. Uceda y E. Mujica, pp: 389-414. Actas del Primer Coloquio sobre la Cultura Moche. Travaux de l'Institut Français d'Études Andines 79. Institut Français d'Études Andines, Lima.

Bawden, G. 1996. The Moche. Blackwell Publishers, London.

Bennett, W. C. 1950. The Gallinazo Group, Viru Valley, Peru. Yale University Publications in Anthropology, Number 43, New Haven

Bernier, H. 2005. Étude archéologique de la production artisanale au site Huacas de Moche, côte nord du Pérou. Tesis doctoral. Département d'Anthropologie, Université de Montréal.

Bourget, S. 2001. "Rituals of Sacrifice: Its practice at Huaca de la Luna and Its Representation in Moche Iconography". En Moche: Art and Political Representation in Ancient Peru, editado por J. Pillsbury, pp: 89-109. National Gallery of Art, Washington, D.C.

Bourget, S. 2003. "Somos Diferentes: dinámica ocupacional del sitio Castillo de Huancaco, valle de Virú”. En Moche: Hacia el final del milenio, editado por S. Uceda y E. Mujica, pp: 245-267. Actas del Segundo Coloquio sobre la Cultura Moche. I. Universidad Nacional de Trujillo y Pontificia Universidad Católica del Perú, Lima.

Castillo, L. J. 1989. Personajes míticos, escenas y narraciones en la iconografía Mochica. Fondo Editorial de la Universidad Católica del Perú, Lima.

Castillo, L. J. 2003. "Los últimos Mochicas en Jequetepeque”. En Moche: Hacia el final del milenio II, editado por: S. Uceda y E. Mujica, pp: 65-123. Actas del Segundo Coloquio sobre la Cultura Moche. Universidad Nacional de Trujillo y Pontificia Universidad Católica del Perú, Lima.

Castillo, L. J. y C. Donnan. 1994. "Los Mochicas del Norte y los Mochicas del Sur. Una perspectiva desde el valle de Jequetepeque”. En Vicús, editado por. K. Makowski, I. Amaro, M. Diez-Canseco, O. Eléspuru y J. A. Murro, pp: 143-176. Banco de Crédito del Perú, Lima.

Chapdelaine, C. 2003a. "La Ciudad de Moche: Urbanismo y Estado". En Moche: Hacia el final del milenio II, editado por S. Uceda y E. Mujica, pp: 247-285. Actas del Segundo Coloquio sobre la Cultura Moche. 
Universidad Nacional de Trujillo y Pontificia Universidad Católica del Perú, Lima.

Chapdelaine, C. 2003b. "Moche Art Style in the Santa Valley: between being "à la mode" and developing a provincial identity". Ponencia presentada en Sibley Conference, Noviembre 2003. University of Texas, Austin.

Chapdelaine, C. 2003c. "State Expansion with or without Warfare: Moche Invasion and Colonization of the Santa Valley, North Coast of Peru". Ponencia presentada en Fourth Complex Society Group Conference, Cotsen Institute of Archaeology, Noviembre 2003. UCLA, Los Angeles.

Chapdelaine, C. 2004a. "Gallinazo and Moche at El Castillo of Santa: An Interlocking History". Ponencia presentada en 23rd Annual Meeting of the Northeast Conference on Andean Archaeology and Ethnohistory, Noviembre 2004. Yale University, New Haven.

Chapdelaine, C. 2004b. "Moche Political Organization in the Santa Valley: A Case of Direct Rule through Gradual Control of the Local Population". Ponencia presentada en el Simposio New Perspectives on Moche Political Organization, Agosto 2004. Dumbarton Oaks, Pontificia Universidad Católica del Perú y Museo Arqueológico Rafael Larco Herrera, Lima

Chapdelaine, C. 2004c. "The Moche Occupation of the Lower Santa Valley and the nature of the Southern Moche State". Ponencia presentada en 69th Annual Meeting of the Society for American Archaeology, 31 de marzo al 4 de abril 2004. Montreal. (www.anthro.umontreal.ca)

Chapdelaine, C. y V. Pimentel. 2001. Informe del Proyecto Arqueológico PSUM (Proyecto Santa de la Universidad de Montreal) 2000. La presencia Moche en el valle de Santa, Costa Norte del Perú. Informe presentado al Instituto Nacional de Cultura (disponible en http:// www.mapageweb.umontreal.ca/chapdelc), Lima.

Chapdelaine, C. y V. Pimentel. 2002. Informe del Proyecto Arqueológico PSUM (Proyecto Santa de la Universidad de Montreal) 2001. La presencia Moche en el valle de Santa, Costa Norte del Perú. Informe presentado al Instituto Nacional de Cultura (disponible en http:// www.mapageweb.umontreal.ca/chapdelc), Lima.

Chapdelaine, C. y V. Pimentel. 2003. Un tejido único Moche III del sitio Castillo de Santa: una escena de cosecha de yuca. Bulletin de l'Institut 
Français d'Etudes Andines 32 (1): 23-50. Lima: Institut Français d'Études Andines.

Chapdelaine, C., G. Kennedy y S. Uceda 1995. "Activación neutrónica en el estudio de la producción local de la cerámica ritual en el sitio Moche, Perú". Bulletin de l'Institut Français d'Études Andines 24 (2): 183-212. Lim

Chapdelaine, C., V. Pimentel y H. Bernier. 2003. Informe del Proyecto Arqueológico PSUM (Proyecto Santa de la Universidad de Montreal) 2002. La presencia Moche en el valle de Santa, Costa Norte del Perú. Informe presentado al Instituto Nacional de Cultura (disponible en http://www.mapageweb.umontreal.ca/chapdelc), Lima.

Chapdelaine, C., V. Pimentel, G. Gagne, J. Gamboa, D. Regalado y D. Chicoine. 2004. "Nuevos datos sobre Huaca China, Valle de Santa, Perú". Bulletin de l'Institut Français d'Études Andines 33 (1): 55-80. Lima: Institut Français d'Études Andines.

Cummins, T. 1994. "La Tradición de figurinas de la costa ecuatoriana: estilo tecnológico y el uso de moldes". En Tecnología y Organización de la cerámica prehispánica en los Andes, editado por I. Shimada, pp: 157172. Fondo Editorial de la Pontificia Universidad Católica del Perú, Lima.

Cummins, T. 1998. "The Figurine Tradition of Coastal Ecuador: technological styles and the use of molds". En Ceramic Production in the Andes: Technology, Organization, and Approaches, editado por I. Shimada, pp: 199-212. University of Pennsylvania Museum of Archaeology and Anthropology, Philadelphia.

De Bock, E. 2003. "Templo de la escalera y ola y la hora del sacrificio humano". En Moche: Hacia el final del milenio I, editado por S. Uceda y E. Mujica, pp: 307-324. Actas del Segundo Coloquio sobre la Cultura Moche. Universidad Nacional de Trujillo y Pontificia Universidad Católica del Perú, Lima.

Donnan, C. 1973. Moche Occupation of the Santa Valley, Peru. University of California Publications in the Anthropology, vol. 8. University of California Press, Berkeley

Donnan, C. 1976. Moche Art and Iconography. UCLA Latin American Center Publications. University of California, Los Angeles. 
Donnan, C. 1978. Moche Art of Peru. Pre-Columbian Symbolic Communication. Fowler Museum of Cultural History, University of California, Los Angeles.

Donnan, C. 2004. Moche Portraits from Ancient Peru. University of Texas Press, Austin.

Donnan, C. y D. McClelland. 1999. Moche Fineline Painting, Its evolution and its artists. Fowler Museum of Cultural History, Los Angeles: UCLA.

Druc, I. 1996. "De la etnografía hacia la arqueología: aportes de entrevistas con ceramistas de Ancash (Perú) para la caracterización de la cerámica prehispánica". Bulletin de l'Institut Français d'Etudes Andines 25(1): $17-41$.

Fogel, H. P. 1993. Settlements in Time: A Study of Social and Political Development during the Gallinazo Occupation of the North Coast of Peru. Ph.D. dissertation. Department of Anthropology. Yale University, New Haven.

Franco, R. Gálvez, C. y S. Vásquez. 2003. "Modelos, función y cronología de la Huaca Cao Viejo, complejo El Brujo". En Moche: Hacia el final del milenio II, editado por S. Uceda y E. Mujica, pp: 125-177. Actas del Segundo Coloquio sobre la Cultura Moche. Universidad Nacional de Trujillo y Pontificia Universidad Católica del Perú, Lima.

Gamboa, J. 2004. "Plazas y cercaduras: una aproximación a la arquitectura pública Moche IV-V en Santa y Moche". Ponencia presentada en Primera Conferencia Internacional de Jóvenes Investigadores sobre la Cultura Mochica. Un simposio organizado en conjunción con la conferencia New Perspectives on Moche Political Organization, Agosto 2004. Dumbarton Oaks, Pontificia Universidad Católica del Perú y Museo Arqueológico Rafael Larco Herrera, Lima.

Gamboa, J. 2005. "Continuidad y cambio en la organización de los espacios arquitectónicos de Huaca de la Luna y Plataforma A de Galindo, costa norte del Perú". Bulletin de l'Institut Français d'Études Andines 34 (2): 161-183.

Grieder, T. 1978. The Art and Archaeology of Pashash. University of Texas, Austin.

Gumerman IV, G. y J. Briceńo. 2003. "Santa Rosa - Quirihuac y Ciudad de Dios: asentamientos rurales en la parte media del valle de Moche". En Moche: Hacia el final del milenio II, editado por. S. Uceda y E. 
Mujica, pp: 217-243. Actas del Segundo Coloquio sobre la Cultura Moche. Universidad Nacional de Trujillo y Pontificia Universidad Católica del Perú, Lima.

Hayashida, F. 1999. "New insights into Inka pottery production". En Ceramic Production in the Andes: Technology, Organization, and Approaches, editado por I. Shimada, pp: 313-335. University of Pennsylvania Museum of Archaeology and Anthropology, Philadelphia.

Hocquenghem, A.-M. 1987. Iconografia Mochica. Fondo Editorial de la Pontificia Universidad Católica del Perú, Lima.

Kaulicke, P. 1992. "Moche, Vicus-Moche y el Mochica Temprano". Bulletin de l'Institut Français d'Études Andines 21(3): 853-903.

Kaulicke, P. 1994. "La presencia Mochica en el Alto Piura: Problemática y Propuestas". En Moche: Propuestas y Perspectivas, editado por. S. Uceda y E. Mujica, pp: 327-358. Actas del Primer Coloquio sobre la Cultura Moche. Travaux de l'Institut Français d'Études Andines 79. Institut Français d'Études Andines, Lima.

Kennedy, G. y C. Chapdelaine. 2004. "Neutron Activation characterization of Moche Ceramics from the Moche Site and the Lower Santa Valley". Ponencia presentada en 69th Annual Meeting of the Society for American Archaeology, Marzo-Abril 2004. Montreal.

Larco Hoyle, R. 1948. Cronología arqueológica del norte del Perú. Sociedad Geográfica Americana, Buenos Aires.

Larco Hoyle, R. 1938. Los Mochicas I. Casa Editora La Crónica y Variedades, Lima.

Larco Hoyle, R. 1939. Los Mochicas II. Casa Editora La Crónica y Variedades, Lima.

Larco Hoyle, R. 2001.Los Mochicas. Museo Arqueológico Rafael Larco Herrera y Fundación Telefónica, Lima.

Makowski, K. 1996. "Los seres radiantes, el águila y el búho. La imagen de la divinidad en la cultura Mochica". En Imágenes y mitos, editado por K. Makowski, I. Amaro y M. Hernández, pp: 13-114. Australis S. A - Fondo Editorial SIDEA, Lima.

Makowski, K. 2003. "La deidad suprema en la iconografía mochica: ¡cómo definirla?”. En Moche: Hacia el final del milenio I, editado por S. Uceda y E. Mujica, pp: 343-381. Actas del Segundo Coloquio sobre 
la Cultura Moche. Universidad Nacional de Trujillo y Pontificia Universidad Católica del Perú, Lima.

Moseley, M. E. 1992. The Incas and their Ancestors. Thames and Hudson, New York.

Pimentel, V. 2004a. "Comparing Mochica Household from Moche and Santa Valleys, North Coast of Peru". Ponencia presentada en 69th Annual Meeting of the Society for American Archaeology, Marzo-Abril de 2004. Montreal.

Pimentel, V. 2004b. "Viviendas Mochica e identidad en los valles de Moche y Santa, Costa Norte del Perú". Ponencia presentada en Primera Conferencia Internacional de Jóvenes Investigadores sobre la Cultura Mochica. Un simposio organizado en conjunción con la conferencia Nuevas Perspectivas en la Organización Política Moche, agosto 2004. Dumbarton Oaks, Pontificia Universidad Católica del Perú y Museo Arqueológico Rafael Larco Herrera, Lima.

Pimentel, V. y M. I. Paredes. 2003. "Evidencias Moche V en tambos y caminos entre los valles de Santa y Chao, Perú". En Moche: Hacia el final del milenio I, editado por S. Uceda y E. Mujica, pp: 269-303. Actas del Segundo Coloquio sobre la Cultura Moche. Universidad Nacional de Trujillo y Pontificia Universidad Católica del Perú, Lima.

Proulx, D. 2004. "Pañamarca and The Moche Presence in the Nepeña Valley Revisited". Ponencia presentada en 69th Annual Meeting of the Society for American Archaeology, Marzo-Abril 2004. Montreal.

Prümers, H. 2001. "El Castillo de Huarmey: una plataforma funeraria del Horizonte Medio". Boletín de Arqueología PUCP 4: 309-312.

Russell, G. y M. Jackson. 2001. "Political Economy and Patronage at Cerro Mayal, Peru". En Moche: Art and Political Representation in Ancient Peru, editado por J. Pillsbury, pp: 159-175. National Gallery of Art, Washington, D.C.

Russell, G., Leonard, B. y J. Briceńo. 1994. "Cerro Mayal: Nuevos datos sobre la producción cerámica Moche en el valle de Chicama”. En Moche: Propuestas y Perspectivas, editado por. S. Uceda y E. Mujica, pp: 181-206. Actas del Primer Coloquio sobre la Cultura Moche. Travaux de l'Institut Français d'Études Andines 79. Institut Français d'Études Andines, Lima. 
Russell, G., Leonard, B. y J. Briceńo. 1998. "The Cerro Mayal Workshop: Addressing issues of craft specialization in Moche Society". En Ceramic Production in the Andes: Technology, Organization, and Approaches, editado por I. Shimada, pp: 63-89. University of Pennsylvania Museum of Archaeology and Anthropology, Philadelphia.

Shimada, I. 1994a. Pampa Grande and the Mochica Culture. University of Texas Press, Austin.

Shimada, I. 1994b. "Los Modelos de organización sociopolítica de la cultura Moche: nuevos datos y perspectivas". En Moche: Propuestas y Perspectivas, editado por. S. Uceda y E. Mujica, pp: 359-387. Actas del Primer Coloquio sobre la Cultura Moche. Travaux de l'Institut Français d'Études Andines 79. Institut Français d'Études Andines, Lima.

Strong, W. y C. Evans. 1952. Cultural Stratigraphy in the Viru Valley, Northern Peru: The Formative and Florescent Epoch. Columbia Studies in Archaeology and Ethnology 4. Columbia University Press, New York.

Taillon-Pellerin, A. 2004. "Ceramic Production at Guad-88: A Secondary Moche Site of the Lower Santa Valley”. Ponencia presentada en 69th Annual Meeting of the Society for American Archaeology, Marzo-Abril 2004. Montreal.

Tschauner, H.; Vetters, L.; Dulanto, J.; Saco, M. y C. Wester. 1994. “Un taller alfarero Chimú en el valle de Lambayeque". En Tecnología y organización de la producción de cerámica prehispánica en los Andes I, editado por I. Shimada, pp: 349-393. Fondo Editorial de la Pontificia Universidad Católica del Perú, Lima.

Uceda, S. 2004. "El complejo arquitectónico religioso Moche de Huaca de la Luna: el templo de la divinidad de las montańas". En Investigaciones en la Huaca de la Luna 1998-1999, editado por S. Uceda y R. Morales, pp:367-375. Universidad Nacional de Trujillo y Proyecto Arqueológico Huacas del Sol y de la Luna, Trujillo.

Uceda, S. y M. Tufinio. 2003. "El complejo arquitectónico religioso Moche de Huaca de la Luna: una aproximación a su dinámica ocupacional”. En Moche: Hacia el final del milenio II, editado por S. Uceda y E. Mujica, pp: 179-228. Actas del Segundo Coloquio sobre la Cultura Moche. Universidad Nacional de Trujillo y Pontificia Universidad Católica del Perú, Lima. 
Uceda, S. y J. Armas. 1997. "Los talleres alfareros en el centro urbano Moche". En Investigaciones en la Huaca de la Luna 1995, editado por S. Uceda, E. Mujica y R. Morales, pp: 93-104. Facultad de Ciencias Sociales de la Universidad Nacional de La Libertad, Trujillo.

Uceda, S. y J. Armas. 1998. "An urban pottery workshop at the site of Moche, North Coast of Peru". En Ceramic Production in the Andes: Technology, Organization, and Approaches, editado por I. Shimada, pp: 91-110. University of Pennsylvania Museum of Archaeology and Anthropology, Philadelphia.

Wilson, D. 1988. Prehispanic Settlement Patterns in the Lower Santa Valley, Peru: A Regional Perspective on the Origins and Development of Complex North Coast Society. Smithsonian Institution Press, Washington, D.C.

Wilson, D. 1995. "Prehistoric Settlement Patterns in the Casma Valley, North Coast of Peru: Preliminary Results to Date". Journal of the Steward Anthropological Society 23 (1-2): 189-227.

Wilson, D. 1997. "Early State Formation on the North Coast of Peru. A critique of the City-State Model". En The Archaeology of City-States, Cross-Cultural Approaches, editado por D. L. Nichols y T. H. Charlton, pp:229-244. Smithsonian Institution Press, Washington, D.C.

Wilson, D. 1999. Indigenous South Americans of the Past and Present, an Ecological Perspective. Westview Press, Boulder. 